\title{
Erythropoietin, Forkhead Proteins, and Oxidative Injury: Biomarkers and Biology
}

\author{
Kenneth Maiese ${ }^{1,2,3,4,5, *}$, Jinling Hou ${ }^{1}$, Zhao Zhong Chong ${ }^{1}$, \\ and Yan Chen Shang ${ }^{1}$ \\ ${ }^{1}$ Division of Cellular and Molecular Cerebral Ischemia, ${ }^{2}$ Departments of Neurology \\ and Anatomy \& Cell Biology, ${ }^{3}$ Barbara Ann Karmanos Cancer Institute, ${ }^{4}$ Center for \\ Molecular Medicine and Genetics, ${ }^{5}$ Institute of Environmental Health Sciences, \\ Wayne State University School of Medicine, Detroit, Michigan
}

E-mail: kmaiese@med.wayne.edu; aa2088@wayne.edu; wntin75@yahoo.com; wntin57@aol.com

Oxidative stress significantly impacts multiple cellular pathways that can lead to the initiation and progression of varied disorders throughout the body. It therefore becomes imperative to elucidate the components and function of novel therapeutic strategies against oxidative stress to further clinical diagnosis and care. In particular, both the growth factor and cytokine erythropoietin (EPO), and members of the mammalian forkhead transcription factors of the $\mathrm{O}$ class (FoxOs), may offer the greatest promise for new treatment regimens, since these agents and the cellular pathways they oversee cover a range of critical functions that directly influence progenitor cell development, cell survival and degeneration, metabolism, immune function, and cancer cell invasion. Furthermore, both EPO and FoxOs function not only as therapeutic targets, but also as biomarkers of disease onset and progression, since their cellular pathways are closely linked and overlap with several unique signal transduction pathways. Yet, EPO and FoxOs may sometimes have unexpected and undesirable effects that can raise caution for these agents and warrant further investigations. Here we present the exciting as well as the complex role that EPO and FoxOs possess to uncover the benefits as well as the risks of these agents for cell biology and clinical care in processes that range from stem cell development to uncontrolled cellular proliferation.

KEYWORDS: aging, Alzheimer's disease, angiogenesis, apoptosis, cancer, cardiac, diabetes, erythropoietin, forkhead transcription factors, immune system, ischemia, neurodegeneration, oxidative stress, sirtuins, stem cells, vascular disease, Wnt, wingless

\section{INTRODUCTION}

\section{Oxidative Stress and Apoptotic Injury}

The generation of reactive oxygen species (ROS) that consist of oxygen free radicals and other chemical entities can result in the development of oxidative stress. Oxygen free radicals can be generated in 
elevated quantities during the reduction of oxygen and lead to cell injury. ROS can involve superoxide free radicals, hydrogen peroxide, singlet oxygen, nitric oxide (NO), and peroxynitrite[1,2,3]. Most species are produced at low levels during normal physiological conditions and are scavenged by endogenous antioxidant systems that include superoxide dismutase (SOD), glutathione peroxidase, catalase, and small molecule substances such as vitamins $\mathrm{C}$ and $\mathrm{E}$. Other closely linked pathways to oxidative stress may be tempered by different vitamins, such as vitamin $\mathrm{D}_{3}[4]$ and the amide form of niacin or vitamin $\mathrm{B}_{3}$, nicotinamide[5,6,7,8,9,10,11].

Initial investigations into oxidative stress may have begun with studies that examined the rate of oxygen consumption in organisms. Work by Pearl proposed that increased exposure to oxygen through a high metabolic rate could lead to a shortened life span[12]. Additional work by other investigators demonstrated that increased metabolic rates could be detrimental to animals in an elevated oxygen environment[13]. Current studies show that oxygen free radicals and mitochondrial DNA mutations have become associated with cellular injury, aging mechanisms, and accumulated toxicity for an organism[14].

Oxidative stress leads to the destruction of multiple cell types through apoptotic pathways[15,16,17] and also through autophagy[18]. However, it has also recently been shown that genes involved in the apoptotic process are replicated early during processes that involve cell replication and transcription, suggesting a much broader role for these genes than originally anticipated[19]. Apoptotic-induced oxidative stress in conjunction with processes of mitochondrial dysfunction[20,21,22] can contribute to a variety of disease states, such as diabetes, ischemia, cognitive loss, Alzheimer's disease[1,23,24], Parkinson's disease[1,25], Huntington's disease[1,26], and trauma [1,23,27,28,29]. Oxidative stress can lead to apoptosis in neurons, endothelial cells (ECs), cardiomyocytes, and smooth muscle cells that involve separate as well as overlapping pathways[27,30,31,32,33,34].

Apoptosis is a dynamic process that consists of both the early exposure of membrane phosphatidylserine (PS) residues and the late destruction of genomic DNA[35,36]. Externalization of membrane PS residues is an early event during cell apoptosis[37,38] and can become a signal for the phagocytosis of cells that is controlled by caspase 1 and caspase $3[17,39,40]$. The loss of membrane phospholipid asymmetry leads to the exposure of membrane PS residues on the cell surface and assists microglia to target cells for phagocytosis[11,32,41,42,43]. This process occurs with the expression of the phosphatidylserine receptor (PSR) on microglia during oxidative stress[44,45]. It has been shown that blockade of PSR function in microglia prevents the activation of microglia[42,46]. Externalization of membrane PS residues occurs in neurons, vascular cells, and inflammatory microglia during reduced oxygen exposure[17,47,48], $\beta$-amyloid (A $\beta$ ) exposure[49,50], NO exposure[51,52,53,54,55], and during the administration of agents that induce the production of ROS, such as 6-hydroxydopamine[56]. Membrane PS externalization on platelets also has been associated with clot formation in the vascular system[57].

The cleavage of genomic DNA into fragments[47,58,59] usually occurs after membrane PS exposure[60] and is considered to be a later event during apoptotic injury[32,59,61,62]. Several enzymes responsible for DNA degradation include the acidic cation-independent endonuclease (DNase II), cyclophilins, and the 97-kDa magnesium-dependent endonuclease[1,63]. Three separate endonuclease activities have also been found in neurons that include a constitutive acidic cation-independent endonuclease, a constitutive calcium/magnesium-dependent endonuclease, and an inducible magnesiumdependent endonuclease[64,65].

During oxidative stress, mitochondrial membrane transition pore permeability is also increased[10,32,66,67], a significant loss of mitochondrial $\mathrm{NAD}^{+}$stores occurs, and further generation of superoxide radicals leads to cell injury[11,68]. Mitochondria are a significant source of superoxide radicals that are associated with oxidative stress[1,69]. Blockade of the electron transfer chain at the flavin mononucleotide group of complex I or at the ubiquinone site of complex III results in the active generation of free radicals, which can impair mitochondrial electron transport and enhance free radical production[44,63]. Furthermore, mutations in the mitochondrial genome have been associated with the potential development of a host of disorders, such as hypertension, hypercholesterolemia, and hypomagnesemia[70,71]. ROS may also lead to cellular acidosis and subsequent mitochondrial 
failure[23]. Disorders, such as hypoxia[72], diabetes[73,74], and excessive free radical production[65,75,76], can result in the disturbance of intracellular $\mathrm{pH}$.

\section{Biomarkers in Health and Disease}

For biological systems, a "biomarker" can consist of any entity that occurs in the body and that can be measured to predict the diagnosis, onset, or progression of a disease process. A biomarker does not have to be confined to a single entity. As a result, the definition of a biomarker is intentionally broad and application of biomarkers can be used for the determination of specific genes, proteins, products of cellular and biological processes, as well as the response of cells or tissues to therapeutic strategies[77].

Interestingly, some biomarkers can offer the additional benefit to function as a surrogate marker to be able to be used to predict clinical outcome in some cases. For example, biomarkers such as estrogen levels may predict the onset of postmenopausal breast cancer and a poor clinical outcome. In other scenarios, biomarkers may suggest the body's attempt to initiate reparative processes. Novel pathways that involve the cytokine and growth factor erythropoietin (EPO) may indicate that the increased presence of this agent during periods of oxidative stress may lead to cellular mechanisms to protect against ROS[78,79,80]. Furthermore, the activation of transcription factors during tumor invasion that control cell cycle regulation, such as of the forkhead family of the "O" class, may suggest the initiation of cell pathways that are attempting to restrict neoplastic growth[81,82,83]. However, reliance on any single biomarker may be imperfect and lead to initially unpredicted outcomes, such as uncontrolled hypertension or cancer with EPO[78,79,84], or the onset of detrimental apoptotic programs with forkhead transcription factors[36]. A number of other pathways that occur in combination with a particular biomarker during oxidative stress may also influence outcome. In the case of breast cancer, studies suggest that the release of androgens, cytokines, or even changes in body mass and exercise can influence outcome as well as alter the predictability of a specific biomarker[85,86]. For these reasons, it becomes imperative to elucidate the components and function of the novel pathways for EPO and forkhead transcription factors during oxidative stress in order to understand their role not only as biomarkers, but also as therapeutic strategies to offer new insight for clinical care for a number of disease entities.

\section{THE GROWTH FACTOR AND CYTOKINE ERYTHROPOIETIN (EPO)}

\section{Historical Perspective for EPO}

EPO was initially known as "hemopoietine", which could stimulate new red blood cell development. In 1906, Carnot and Deflandre demonstrated that plasma removed from rabbits following a bleeding stimulus that was later injected into control, untreated rabbits would lead to the development of immature red blood cells $[78,79,87,88]$. A number of other investigators followed these studies and found similar results demonstrating that plasma from bled animals would yield a significant reticulocytosis[89,90,91]. More elegant experiments eventually demonstrated that a rise in hemoglobin levels with reticulocytosis occurred in parabiotic rats when only one partner was exposed to hypoxia, illustrating that depressed oxygen tensions could stimulate EPO production[92]. Later, human EPO protein was purified, which led the way for the cloning of the EPO gene and the development of recombinant EPO for clinical use[93,94].

\section{Structure and Chemical Properties for EPO}

The EPO gene is located on chromosome 7, exists as a single copy in a 5.4-kb region of the genomic DNA, and encodes a polypeptide chain containing 193 amino acids. During the production and secretion of EPO, a 166-amino-acid peptide is initially generated following the cleavage of a 27 -amino-acid 
hydrophobic secretory leader at the amino-terminal. In addition, a carboxy-terminal arginine in position 166 is removed both in the mature human and recombinant human EPO (rhEPO), resulting in a circulatory mature protein of 165 amino acids[80,95]. Once a mature protein, EPO becomes a 30.4-kDa glycoprotein with approximately half of its molecular weight derived from carbohydrates that can vary among species[80]. EPO contains four glycosylated chains, including three $N$-linked and one $O$-linked acidic oligosaccharide side chains. The glycosylated chains are important for the biological activity of EPO and can protect EPO from oxygen radical degradation. EPO is stabilized by the carbohydrate chains[96]. The oligosaccharides in EPO may also protect the protein from oxygen radical activity[97]. The N-glycosylated chains are believed to contribute to the thermal stability of EPO[98]. In addition, the $N$ - and $O$-linked chains may be necessary for the production and secretion of the mature EPO[99]. The presence of the carbohydrates is also important in the control of the metabolism of EPO, since EPO molecules with high sialic acid content can be easily cleared by the body through specific binding in the liver[100]. In addition, the biological activity of EPO also relies on two disulfide bonds formed between cysteines at positions 7 and 160, and at positions 29 and 33[95].

\section{Expression and Regulation of EPO and the EPO Receptor}

The principal organs of EPO production and secretion are the kidney, liver, brain, and uterus. EPO production and secretion occurs foremost in the kidney[101]. The kidney peritubular interstitial cells are responsible for the production and secretion of EPO[88]. With the use of cDNA probes derived from the EPO gene, peritubular ECs, tubular epithelial cells, and nephron segments in the kidney have also been demonstrated to be vital cells for the production and secretion of EPO[102,103]. During periods of acute renal failure, EPO may provide assistance for the protection of the kidneys and nephrons[104,105,106]. Other sites of EPO production and secretion occur in the liver and the uterus[107]. Hepatocytes, hepatoma cells, and Kupffer cells of the liver can produce EPO and, in turn, EPO may protect these cells from injury and assist with regeneration[108,109]. In regards to the uterine production of EPO, it is believed that the occurrence of neonatal anemia that can take place in the early weeks after birth may partly result from the loss of EPO production and secretion by placenta[110]. In addition, increased levels of EPO in the fetal plasma and amniotic fluid during gestation may function as a biomarker of intrauertine hypoxia[111].

Although EPO is approved by the U.S. Food and Drug Administration for the treatment of anemia, recent studies demonstrated that EPO is not only required for erythropoiesis, but also functions in other organs and tissues, such as the brain, heart, and vascular system[46,112,113,114,115,116]. EPO production is believed to occur throughout the body[3,80,117] and can be detected in the breath of healthy individuals[118]. In addition, it has been suggested that EPO may provide developmental cognitive support. In experimental animal models, EPO may reduce apoptotic pathways during periods of hyperoxia in the developing brain[119,120]. Furthermore, clinical disorders may have periods of hyperoxia followed by cerebral hypoperfusion and hypoxia that can lead to cerebral injury with associated oxidative stress[121]. In these circumstances, EPO may also be protective, since it can promote neurite outgrowth[122] and may also regulate hemoglobin levels that have recently been associated with cognitive decline[123]. In other work, elevated EPO concentrations during infant maturation were correlated with increased Mental Development Index scores[124] and EPO may prevent the toxic effects of agents used to control cognitive function, such as haloperidol[125].

However, new knowledge that EPO and its receptor are present in the nervous and vascular systems has generated great enthusiasm for the potential clinical applications of EPO, such as in Alzheimer's disease, Parkinson's disease[126], cardiac insufficiency[127,128,129,130], cardiac transplantation[131,132], and during coronary artery bypass surgery to prevent renal injury[133]. In the nervous system, primary sites of EPO production and secretion are in the hippocampus, internal capsule, cortex, midbrain, cerebral ECs, and astrocytes $[80,95,134,135]$. Further work has revealed several other organs as secretory tissues for EPO that include peripheral ECs[136], myoblasts[137], insulin-producing cells[138], and cardiac tissue[80,101]. 
EPO controls erythroid cell proliferation, differentiation, and survival through its binding to a target cell surface receptor, the EPO receptor (EPOR)[139] (Fig. 1). The EPOR is also expressed in numerous nonerythroid blood lines that include neurons, microglia, astrocytes, and in cerebral ECs[80,95,101,135,136], as well as on myelin sheaths of radicular nerves in human peripheral nerves[140], suggesting both a developmental and potential protective role for EPO in the central and peripheral nervous systems. During gestation, EPO production is increased, but later becomes suppressed following birth to be regulated by the tissue oxygen supply[141]. The EPOR is also expressed in primary cerebral ECs[67,80] as well as in human umbilical veins, bovine adrenal capillaries, and rat brain capillaries[136,142].

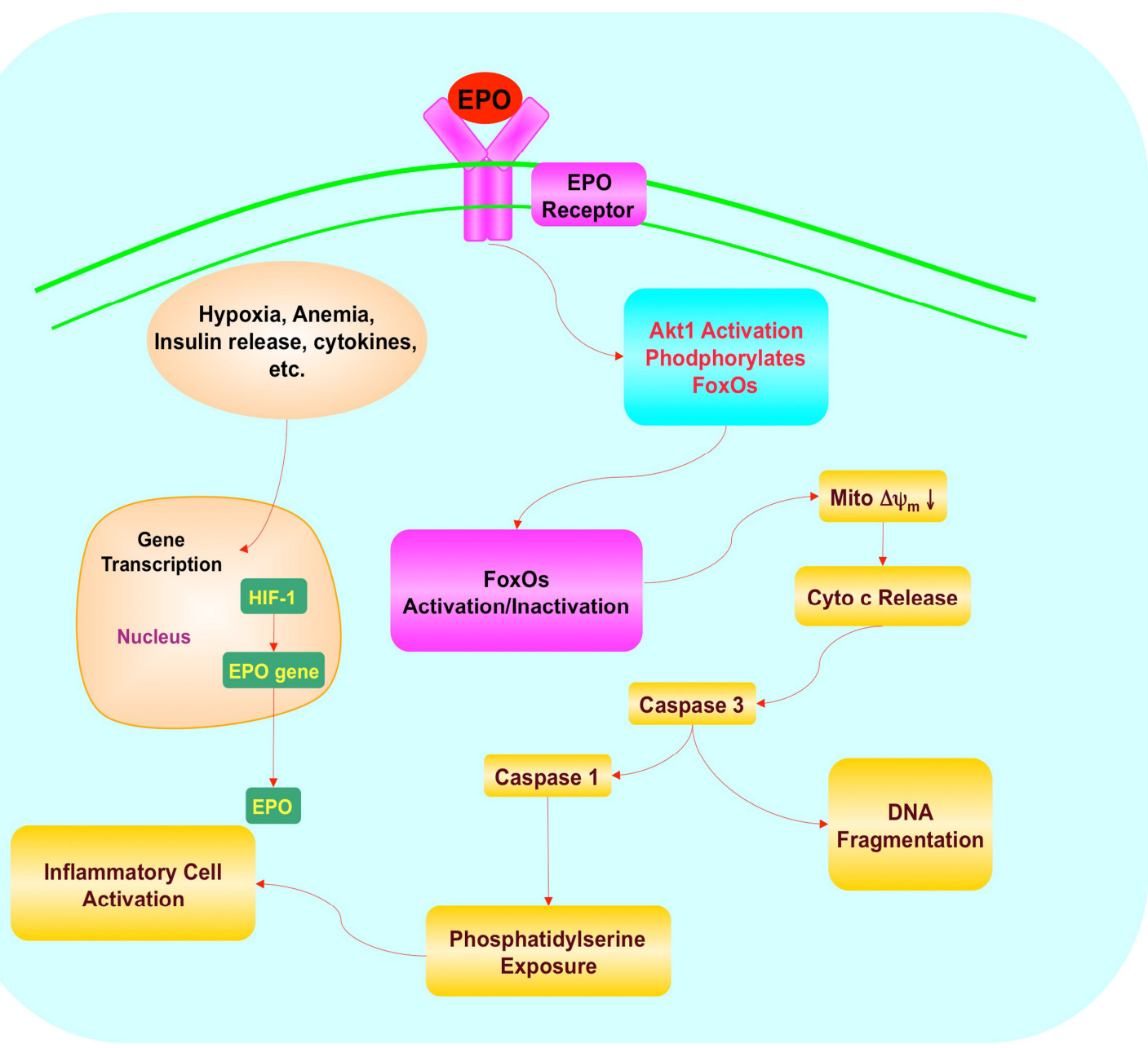

FIGURE 1. EPO and forkhead transcription factors (FoxOs) control cell survival and inflammatory cell activation. EPO through the EPOR and FoxOs can modulate cell survival and control inflammatory cell activation through pathways that involve hypoxiainducible factor 1 (HIF-1) activation (occurs through several stimuli, such as hypoxia, anemia, insulin release, and cytokine exposure), gene transcription, protein kinase B (Akt), mitochondrial membrane potential $\left(\Delta \Psi_{\mathrm{m}}\right)$, cytochrome c (Cyto-c), and caspases. These pathways can then regulate the onset of early apoptotic injury with PS exposure, late injury with nuclear DNA degradation, and inflammatory cell activation.

Despite the fact that EPO is a critical modulator of erythropoiesis, the presence of a diminished oxygen tension is required, rather than a low concentration of red blood cells[3,78,79,143]. In most tissues, including the brain, hypoxia-dependent expression of EPO and the EPOR are controlled by 
hypoxia-inducible factor 1 (HIF-1). HIF-1 is essential for the production and secretion of EPO in response to hypoxia. At the transcriptional level, the hypoxia-dependent gene transcription of EPO and the EPOR directly results from the activation of the HIF-1 pathway under hypoxic conditions. Gene transcription of EPO is mediated by the transcription enhancer located in the 3'-flanking region of the EPO gene that specifically binds to HIF-1[80,95]. Yet, hypoxia is not the only condition that can alter the expression of EPO and the EPOR. The production and secretion of EPO in female reproductive organs is estrogen dependent. During the cyclic development of the uterine endometrium, $17 \beta$-estradiol can lead to a rapid and transient increase in EPO mRNA in the uterus[144], oviducts, and ovaries[145]. Hypoxic-induced EPO mRNA expression in uterine tissue occurs only in the presence of $17 \beta$-estradiol. EPO mRNA expression by hypoxia in the uterus is less pronounced than the EPO expression that occurs in the kidney and the brain[146]. Interestingly, a variety of cellular disturbances may lead to either increased or decreased EPO expression through the control of HIF, such as hypoglycemia, cadmium exposure, raised intracellular calcium, or intense neuronal depolarizations generated by mitochondrial ROS[135,141,147]. Anemic stress, insulin release, and several cytokines, including insulin-like growth factor, tumor necrosis factor- $\alpha$ (TNF- $\alpha$ )[148], interleukin-1 $\beta$ (IL-1 $\beta$ ), and interleukin-6 (IL-6)[149], can also lead to increased expression of EPO and the EPOR[80,95], and may provide a feedback loop that is regulated by EPO, such as TNF- $\alpha[150]$ (Fig. 1).

\section{FORKHEAD TRANSCRIPTION FACTORS OF THE "O” CLASS}

\section{Background and Structure for FoxOs}

Mammalian forkhead transcription factors of the $\mathrm{O}$ class (FoxOs) function to either block or activate target gene expression[83]. These proteins must bind to DNA through the forkhead domain that relies on 14 protein-DNA contacts. The forkhead domain in Fox proteins consists of three $\alpha$-helices, three $\beta$ sheets, and two loops that are referred to as the wings[151], but not all winged helix domains are considered to be Fox proteins[152]. The forkhead domain is described as a "winged helix" as a result of a butterfly-like appearance on X-ray crystallography[151] or nuclear magnetic resonance imaging[153]. High sequence homology is present in the $\alpha$-helices and $\beta$-sheets, with variations described in either absent $\beta$-sheets and loops or additional $\alpha$-helices. Although both the first and second loops make contact with DNA, it is the second loop that can influence the stability of DNA binding. In addition, posttranslational modification of FoxO proteins, such as phosphorylation or acetylation that block FoxO activity, alter the binding of the C-terminal basic region to DNA to prevent transcriptional activity[154]. Yet, other mechanisms may influence DNA binding of forkhead proteins, such as variations in the Nterminal region of the DNA recognition helix, changes in electrostatic distribution, and the ability of forkhead proteins to be shuttled to the cell nucleus[81,155].

In regards to the forkhead family, at least 100 forkhead genes and 19 human subgroups that range from FOXA to FOXS are now known to exist since the initial discovery of the fly Drosophila melanogaster gene forkhead[156]. The original nomenclature for these proteins, such as forkhead in rhabdomyosarcoma $(F K H R)$, the Drosophila gene fork head $(f k h)$, and Forkhead RElated ACtivator (FREAC)-1 and -2, has been replaced. The current nomenclature for human Fox proteins places all letters in uppercase, otherwise only the initial letter is listed as uppercase for the mouse, and for all other chordates, the initial and subclass letters are in uppercase[157]. FoxOs were first reported in fusion genes in human soft-tissue tumors and leukemias. FOXO1, termed forkhead in rhabdomyosarcoma (FKHR), and FOXO3a, also known as FKHRL1 (forkhead in rhabdomyosarcoma like protein 1), and their genes were identified through chromosomal translocations in alveolar rhabdomyosarcoma tumors[158]. The acute leukemia fusion gene located in chromosome $\mathrm{X}(A F X)$, also known as the FOXO4 gene, was demonstrated as a gene that fused to MLL transcription factor as a result of the $t(X ; 11)$ chromosomal 
translocation in acute lymphoblastic leukemia[159]. A fusion between FOXO2 and MLL also occurs in some cases of acute myeloid leukemia that may be identical to FOXO3a[160].

\section{Expression and Regulation of FoxO Proteins}

FoxO proteins (FoxO1, FoxO3, FoxO4, and FoxO6) are present throughout the body and are expressed in tissues of the reproductive system of males and females, skeletal muscle, the cardiovascular system, lung, liver, pancreas, spleen, thymus, and the nervous system[81,82,83,143,161,162,163,164,165,166,167] (Fig. 2). Interestingly, FoxO proteins are not equally expressed in all tissues, suggesting that individual FoxO proteins may have specificity in regards to cellular function[166]. For example, FoxO6 expression is found in several regions of the brain that play a significant role in cognitive function and emotion, such as the hippocampus, the amygdala, and the nucleus accumbens[164]. In contrast, FoxO1 may be more suited for the control of motor function and memory formation, since the expression of this protein is primarily in the striatum and subregions of the hippocampus[164]. In addition, FoxO3 is more diffusely represented in the hippocampus, cortex, and cerebellum, suggesting a complementary role for this FoxO protein to control cognitive and motor function. FoxO expression can be variable in other tissues[83]. Although studies in mice have shown that the mRNA distribution of Foxo1, Foxo3a, and Foxo4 is similar in the embryo and adult[162], Foxo1 expression was highest in adipose tissue, Foxo3a expression was greatest in the liver, and Foxo4 expression was strongest in muscle[162]. Subsequent work in mice has described Foxo1 expression in all tissues with high levels in the ovaries[168]. Foxo3a also is expressed in all tissues and Foxo4 expression was considered to be more tissue specific in skeletal muscle[168].

Post-translational control of FoxO proteins employs pathways associated with ubiquitylation and acetylation[169,170]. IKB kinase (IKK) can phosphorylate and block the activity of FoxO proteins, such as FoxO3a[81,158]. This leads to the proteolysis of FoxO3a via the Ub-dependent proteasome pathway[81,158,171,172,173]. FoxO proteins are also acetylated by histone acetyltransferases that include $\mathrm{p} 300$, the CREB-binding protein (CBP), and the CBP-associated factor. In addition, FoxO proteins are deacetylated by histone deacetylases. These include Sirt1, a NAD ${ }^{+}$-dependent deacetylase, and the mammalian ortholog of the silent information regulator 2 (Sir2) protein[81], that can control multiple processes such as cell injury, life span, and metabolism[174,175]. Acetylation of FoxO proteins provides another avenue for the control of these proteins. Once acetylated such as by CBP, FoxO proteins may translocate to the cell nucleus, but have diminished activity, since acetylation of lysine residues on FoxO proteins has been shown to limit the ability of FoxO proteins to bind to DNA[176]. Acetylation also can increase phosphorylation of FoxO proteins by the serine-threonine kinase protein kinase $\mathrm{B}$ (Akt)[176].

In addition to acetylation and ubiquitylation, post-translational modulation of FoxO proteins also involves pathways associated with phosphorylation[81,158,171,172,173]. Protein phosphorylation is a critical pathway in the scheme for protein regulation[177]. Akt is a primary mediator of phosphorylation of FoxO1, FoxO3a, and FoxO4 that can block activity of these proteins[158,178] (Fig. 1). Akt phosphorylation of FoxO proteins not only retains these transcription factors in the cytoplasm, but also leads to ubiquitination and degradation through the $26 \mathrm{~S}$ proteasome[170,171]. The serum- and glucocorticoid-inducible protein kinase (Sgk), a member of a family of kinases termed AGC (protein kinase A/protein kinase G/protein kinase C) kinases that includes Akt, can also phosphorylate and retain FoxO3a in the cytoplasm[179]. Knowledge that Sgk and Akt can phosphorylate FoxO3a at different sites suggests other avenues to prevent more effectively apoptotic cell injury that may be mediated by FoxO3a activity. Yet, phosphorylation of FoxO proteins does not always lead to negative regulation. The protein kinase mammalian sterile 20-like kinase-1 can also phosphorylate FoxO proteins directly and lead to their activation[180]. The ability of sterile 20-like kinase-1 to activate FoxO proteins may be linked to c-Jun Nterminal kinase (JNK), since sterile 20-like kinase-1 can increase JNK activation[181]. 


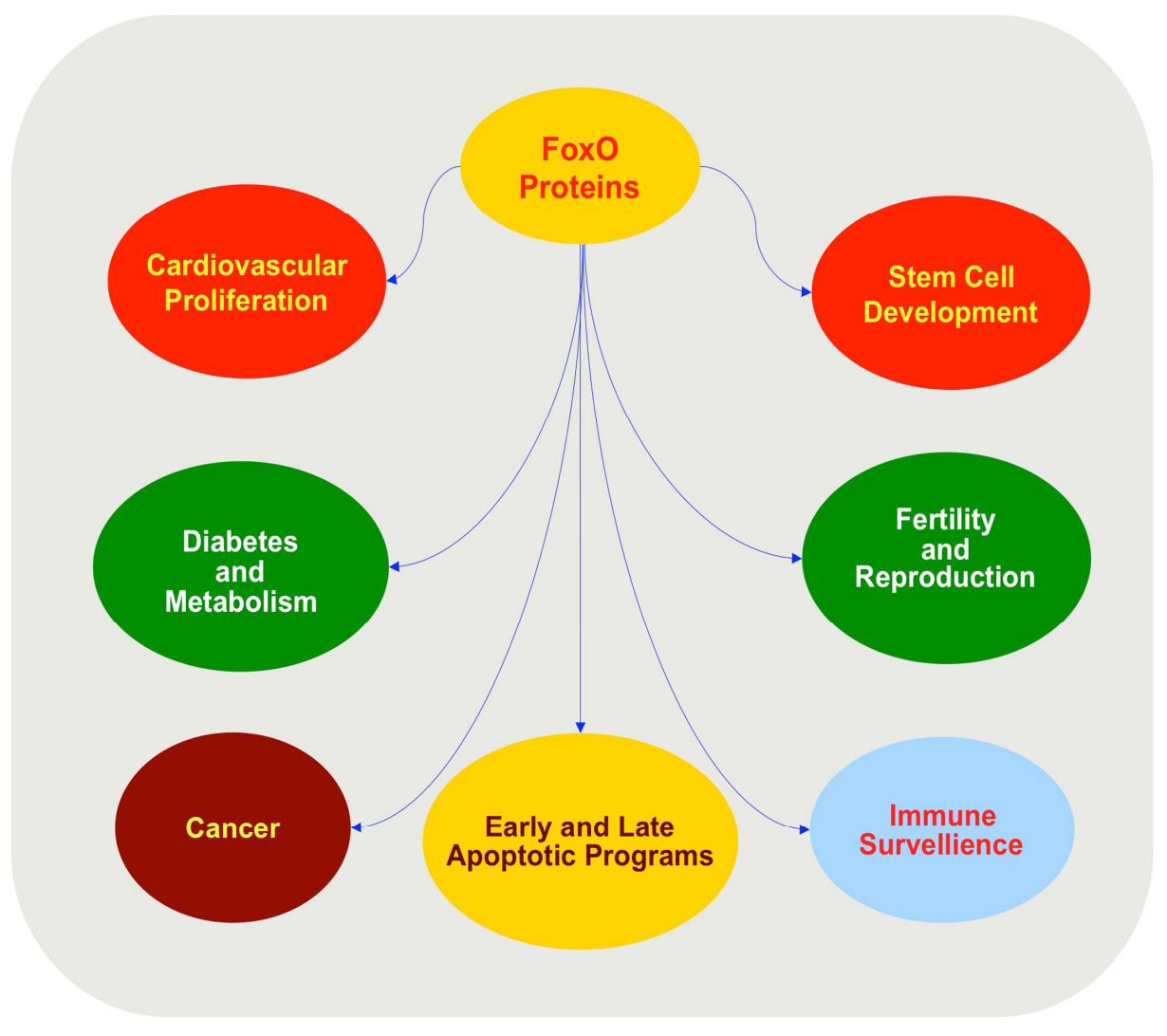

FIGURE 2. FoxO proteins govern a broad range of functions in the body. As transcription factors, FoxO proteins modulate multiple systems in the body. These include the initiation and development of stem cells, proliferation of the cardiovascular system, control of fertility and reproduction, modulation of metabolic pathways during homeostasis and disorders such as diabetes, immune system activation and surveillance, and the ultimate control of cell survival through early and late programs of apoptosis that can limit cancer progression.

Interestingly, activation of Akt in pathways that involve EPO or FoxOs is usually cytoprotective, but may mediate other processes. For example, Akt either alone or through EPO can lead to cell proliferation[182], blood-brain barrier permeability[183], cell protection during inflammation[184,185], neurodegeneration[186], hyperglycemia[187,188], hypoxia[112], A $\beta$ toxicity[49,189,190,191,192], excitotoxicity[193], cardiomyopathy[194], cellular aging[195], and oxidative stress[30,32,42]. In addition, Akt can prevent cellular apoptosis through the phosphorylation of FoxO proteins[3]. Posttranslational phosphorylation of FoxO proteins, such as during EPO administration, will maintain FoxO transcription factors in the cytoplasm by association with 14-3-3 proteins and prevent the transcription of proapoptotic target genes[80,113]. An exception to these observations involving the subcellular trafficking of FoxO proteins involves FoxO6. This FoxO protein usually resides in the nucleus of cells and is phosphorylated by Akt in the nucleus. FoxO6 does not contain a conserved C-terminal Akt motif, which limits nuclear shuttling of this protein, but FoxO6 transcriptional activity can be blocked by growth factors independent of shuttling to the cytosol through a FoxO6 N-terminal Akt site[196].

Modulation of Akt activity also controls apoptotic pathways of caspases that may offer an alternative mechanism to regulate FoxO proteins[82]. Caspases are a family of cysteine proteases that are synthesized as inactive zymogens that are proteolytically cleaved into subunits at the onset of apoptosis[44,197,198]. The caspases 1 and 3 have been linked to the apoptotic pathways of genomic DNA cleavage, cellular membrane PS exposure, and activation of inflammatory cells[46,60,67] (Fig. 1). Caspase pathways may be tied to the forkhead transcription factor FoxO3a, since increased activity of 
FoxO3a can result in cytochrome c release and caspase-induced apoptotic death[113,199,200,201]. Pathways that can inhibit caspase 3 appear to offer a unique regulatory mechanism. For example, studies suggest that cell death pathways that rely on FoxO3a also appear to involve caspase 3 activation[50]. FoxO3a activity promotes caspase-induced apoptotic death[113,199,200,201], but inhibition of caspase 3 can also maintain the phosphorylated "inactive" state of FoxO3a to prevent cell injury[113,199,200]. Other work has shown that caspase 3 activity and cleavage is promoted during transfection of a triple mutant FoxO3a expression in which three phosphorylation sites have been altered to prevent inactivation of FoxO3a[202]. Furthermore, FoxO3a may control early activation and subsequent apoptotic injury in microglia during $A \beta$ exposure through caspase 3[50]. Since $A \beta$ exposure can facilitate the cellular trafficking of FoxO3a from the cytoplasm to the cell nucleus to lead potentially to "proapoptotic" programs by this transcription factor[50], one program in particular that may be vital for apoptotic injury appears to involve the activation of caspase $3 . A \beta$ exposure leads to a rapid and significant increase in caspase 3 activity within 6 h following $A \beta$ administration, but this induction of caspase 3 activity by $A \beta$ requires FoxO3a, since loss of FoxO3a through gene silencing prevents the induction of caspase 3 activity by $\mathrm{A} \beta$.

\section{EPO, FOXOS, AND CELLULAR METABOLISM}

Both EPO and FoxOs play a significant role during cellular metabolism and metabolic disorders such as diabetes mellitus (DM). DM is a significant health concern for both younger and older populations[203,204]. Almost 18-20 million individuals in the U.S. and more than 165 million individuals worldwide suffer from DM. By the year 2030, it is predicted that more than 360 million individuals will be afflicted with DM and its debilitating conditions. Type 2 DM represents at least $80 \%$ of all diabetics, and is dramatically increasing in incidence as a result of changes in human behavior and increased body mass index[203,205]. Type 1 insulin-dependent DM is present in 5-10\% of all diabetics, but is increasing in adolescent minority groups[203,205]. Furthermore, the incidence of undiagnosed diabetes and impaired glucose tolerance in the population raises additional concerns.

Patients with DM can develop immune dysfunction[206], cognitive disorders[206,207], hepatic dysfunction[208], renal disease[209], hematological disease[210], neurodegenerative disorders[2,143,205], and cardiovascular disease[205,211]. Interestingly, the development of insulin resistance and the complications of DM can be the result of cellular oxidative stress[203,205]. Hyperglycemia can lead to increased production of ROS in ECs, liver cells, and pancreatic $\beta$-cells[203,204,205]. Recent clinical correlates support these experimental studies to show that elevated levels of ceruloplasmin are suggestive of increased ROS[203,204,205]. Furthermore, acute glucose swings in addition to chronic hyperglycemia can trigger oxidative stress mechanisms, illustrating the importance for therapeutic interventions during acute and sustained hyperglycemic episodes[203,205].

In regards to EPO during DM, plasma EPO is often low in diabetic patients with anemia[212] or without anemia[213]. The inability of these individuals to produce EPO in response to a declining hemoglobin level suggests an impaired EPO response in diabetic patients[214]. However, increased EPO secretion during diabetic pregnancies may represent the body's attempt at endogenous protection against the complications of DM[215]. Similar to the potential protective role of insulin[216], EPO administration has been shown both in diabetics as well as nondiabetics with severe, resistant, congestive heart failure to decrease fatigue, increase left ventricular ejection fraction, and significantly decrease the number of hospitalization days[217]. In vitro studies with vascular cells exposed to elevated glucose have also demonstrated that EPO can significantly improve EC survival in a 1.0-ng/ml range[218]. EPO administration in patients can also significantly increase plasma levels of EPO well above this range of $1.0 \mathrm{ng} / \mathrm{ml}$ that has been associated with potential EPO cellular protection in patients with cardiac or renal disease[219,220], suggesting that the effects of EPO observed during in vitro studies may parallel the cellular processes altered by EPO in patients with DM[124]. Furthermore, EPO during elevated glucose 
and similar to other models of oxidative stress can block neuronal degeneration[221] and apoptotic DNA degradation in ECs in cardiac and vascular cell models[67,112,113,115,222]. Protection by EPO also is related to the maintenance of mitochondrial membrane potential $\left(\Delta \Psi_{\mathrm{m}}\right)$. Loss of $\Delta \Psi_{\mathrm{m}}$ through the opening of the mitochondrial permeability transition pore represents a significant determinant for cell injury and the subsequent induction of apoptosis[28,69]. EPO has the capacity to prevent the depolarization of the mitochondrial membrane that also affects the release of cytochrome $\mathrm{c}[51,112,223]$.

Additional work suggests that proteins derived from the Drosophila Wingless $(\mathrm{Wg})$ and the mouse Int-1 genes may be associated with the complications of DM[36]. The Wnt proteins are secreted cysteinerich glycosylated proteins that can control cell proliferation[224,225], differentiation, survival, and tumorigenesis[45,226]. These genes are present in several cellular populations[227], such as neurons, cardiomyocytes, ECs, cancer cells, and preadipocytes[2]. Abnormalities in the Wnt pathway, such as with transcription factor 7-like 2 gene, may impart increased risk for type 2 DM in some populations[228,229,230] as well as have increased association with obesity[231]. Yet, intact Wnt family members may offer glucose tolerance and increased insulin sensitivity[232] as well as protect glomerular mesangial cells from elevated glucose-induced apoptosis[233]. These observations suggest a potential protective cellular mechanism for EPO through Wnt signaling. Cell culture studies demonstrate that the Wnt1 protein is necessary and sufficient to impart cellular protection during elevated glucose exposure[218]. EPO maintains the expression of Wnt1 during elevated glucose exposure and prevents loss of Wnt 1 expression that would occur in the absence of EPO during elevated glucose. In addition, blockade of Wnt 1 with a Wnt1 antibody can neutralize the protective capacity of EPO, illustrating that Wnt1 is a critical component in the cytoprotection of EPO during elevated glucose exposure[218].

Metabolic signaling with FoxOs is conserved among multiple species including Caenorhabditis elegans, D. melanogaster, and mammals (Fig. 2). FoxO proteins are homologous to the transcription factor DAuer Formation-16 (DAF-16) in the worm C. elegans that can determine metabolic insulin signaling and lead to life span extension[234,235], suggesting a significant role for FoxO proteins in relation to mammalian cell function[81,158]. FoxO proteins can stimulate the insulin-like growth factor binding protein-1 (IGFBP1) promoter by binding to the insulin-responsive sequence (IRS)[236]. Both insulin and insulin-like growth factor-1 (IGF-1) can suppress this activity through activation of Akt[236,237].

Analysis of the genetic variance in FOXOla and FOXO3a on metabolic profiles, age-related diseases, fertility, fecundity, and mortality in patients has observed higher $\mathrm{HbA}_{1 \mathrm{c}}$ levels and increased mortality risk associated with specific haplotypes of FOXO1a[238]. These clinical observations may coincide with the demonstration in human endothelial progenitor cells that elevated glucose levels can reduce posttranslational phosphorylation of FOXO1, FOXO3a, and FOXO4, and allow for the nuclear translocation of these proteins to initiate an apoptotic program in endothelial progenitor cells[239]. In experimental models, FoxO proteins may prevent the toxic effects of high serum glucose levels. Interferon- $\gamma$-driven expression of tryptophan catabolism by cytotoxic T-lymphocyte antigen 4 may activate Foxo3a to protect dendritic cells from injury in nonobese diabetic mice[240]. Additional studies demonstrated that adipose tissue-specific expression of Foxo1 in mice improved glucose tolerance and sensitivity to insulin during an elevated fat $\operatorname{diet}[241]$. FoxO proteins may also protect against diminished mitochondrial energy levels known to occur during insulin resistance, such as in the elderly populations[203,204205]. In caloricrestricted mice that have decreased energy reserves, Foxo1, Foxo3a, and Foxo4 mRNA levels were noted to increase progressively over a 2-year course[163]. These observations complement studies in Drosophila and mammalian cells that demonstrate an increase in insulin signaling to regulate cellular metabolism during the up-regulation of FoxO1 expression[242].

It should be noted that the ability for FoxO proteins to maintain proper physiologic controls over cellular metabolism may be limited and occur only during specific circumstances. For example, mice with a constitutively active Foxo1 transgene have increased microsomal triglyceride transfer protein and elevated plasma triglyceride levels[243]. Studies in cardiomyocytes also suggest detrimental results with enhanced FoxO activity. Increased transcriptional activity of FoxO1, such as by the Sirt1 activator resveratrol, can diminish insulin-mediated glucose uptake and result in insulin resistance[244]. 
Overexpression of Foxo1 in skeletal muscles of mice also can lead to reduced skeletal muscle mass and poor glycemic control[245], illustrating that activation of FoxO proteins may also impair cellular energy reserves. Other studies that block the expression of Foxo1 in normal and cachectic mice[246], or reduce FoxO3 expression[247], show the reverse, with an increase in skeletal muscle mass or resistance to muscle atrophy. These results become especially relevant in patients with cancer and cachexia, since FoxO protein expression may further muscle wasting for these individuals. With this in mind, one potential agent to consider for the maintenance of cellular metabolism in patients is nicotinamide[11,44,248], an agent that can also inhibit FoxO protein activity[200]. In patients with DM, oral nicotinamide protects $\beta$-cell function, prevents clinical disease in islet-cell antibody-positive firstdegree relatives of type-1 DM, and can reduce $\mathrm{HbA}_{1 \mathrm{c}}$ levels[11,44,203]. Nicotinamide, which is closely linked to cell longevity pathways[249,250], may derive its protective capacity through two separate mechanisms of post-translational modification of FoxO3a. Nicotinamide not only can maintain phosphorylation of FoxO3a and inhibit its activity, but can also preserve the integrity of the FoxO3a protein to block FoxO3a proteolysis that can yield proapoptotic amino-terminal fragments[200].

\section{EPO, FOXOS, STEM CELL PROLIFERATION, AND VASCULOGENESIS}

The observation that EPO may promote tumor proliferation[84,251] and the initial identification of FoxO proteins in soft-tissue tumors and leukemias, neoplasms now believed to contain cancer stem cells for tumor self-renewal[252], suggests that EPO and FoxO proteins may be closely tied to stem cell proliferation and differentiation. In regards to cell development for EPO, it can promote angiogenesis[67,107,112]. EPO has both a mitogenic and chemotactic effect that can lead to matrix metalloproteinase-2 production, cell proliferation, and vessel formation in EC lines[80,95]. In cultured human and bovine ECs, EPO stimulates EC proliferation and fosters the migration of ECs[253]. In neonatal mesenteric microvascular ECs, EPO also leads to vasculogenesis[254]. Angiogenesis by EPO offers an additional level of cytoprotection in various cell systems. For example, in models of cerebral ischemia, EPO promotes factors for angiogenesis, such as Tie-2 and Angiopoietin-2, that may assist with the restoration of cerebral blood flow to preischemic levels[255]. EPO-controlled angiogenesis may also play a significant role during renal inflammation and prevention of allograft rejection[256]. In addition, EPO may promote the viability of transplanted marrow stromal cells and enhance capillary density during experimental cardiac ischemia[257]. Although EPO-induced angiogenesis may impart beneficial effects to ischemic cells of the nervous and cardiovascular systems for nutrient and oxygen supply, other scenarios that involve ocular neovascularization may also seek to block or limit angiogenesis by EPO to prevent disease progression[258]. In clinical studies, EPO serum levels are also significantly associated with the number and function of circulating endothelial progenitor cells, and EPO can stimulate postnatal neovascularization by increasing endothelial progenitor cell mobilization from the bone marrow[259]. Recently, EPO has been shown to increase the motility of human bone marrow multipotent stromal cells[260], suggesting that EPO may lead to increased cell viability during oxidative stress via progenitor cell recruitment[261,262,263]. Interestingly, the ability of EPO to foster eythroid progenitor cell development is dependent on the inhibition of FoxO3a activity[79,80], but may also require regulation of specific gene expression through an EPO-FoxO3a association to promote erythropoiesis in cultured cells[264]. In addition, a close association with EPO[80,117,265] may also be required to modulate FoxO protein activity, such as during erythroid progenitor cell development[78,79], further indicating that use of EPO in patients with combined anemia and cancer may have unexpected detrimental effects[79,80].

When one considers progenitor cell proliferation for FoxO proteins, either simultaneous deletion of Foxol, Foxo3a, and Foxo4, or single deletion of Foxo3a in mice prevents the repopulation of hematopoietic stem cells and leads to apoptosis in these stem cell populations[266,267] (Fig. 2). In regards to the reproductive potential of an organism, deletion of the FoxO3a gene results in the depletion of oocytes and subsequent infertility[268]. Other work using a mouse model of FoxO3a overexpression in oocytes suggests that FoxO3a also may retard oocyte growth and follicular development, and leads to 
anovulation and luteinization of unruptured follicles[269]. In clinical studies, a small percentage of women who suffer from premature ovarian failure have mutations in FOXO3a and FOXO1a[270]. In neuronal populations, FoxOs also may prevent stem cell proliferation, since the proliferation of human neural progenitor cells appears to require the inhibitory phosphorylation of FOXO3a[271].

Similar to EPO, FoxO proteins also play a significant role to modulate new vessel growth that can impact on cardiovascular development. FoxO proteins are intimately involved in EC development and angiogenesis. For example, Foxo3a $a^{-1-}$ and $\mathrm{FoxO}^{-1-}$ mice develop without incidence and are indistinguishable from control littermates. However, mice that are singly deficient in Foxol die by embryonic day 11 and lack development of the vascular system[272]. Additional studies illustrate that EC colonies in Foxol-deficient mice fail to respond to vascular endothelial growth factor in a manner similar to wild-type ECs[273], suggesting that FoxOs are necessary for the development of vascular cells as well as for the biological response to cellular mediators.

During cardiac development, FoxO proteins also appear to be necessary to modulate cardiomyocyte proliferation. Both FoxO1 and FoxO3 are expressed during embryonic through prenatal stages in the developing myocardium. The expression of these FoxO proteins is believed to regulate cardiomyocyte growth negatively, since overexpression of FoxO1 blocks cardiomyocyte proliferation, but expression of dominant-negative FoxO1 leads to enhanced cardiomyocyte growth[274]. These observations may provide clues into the roles of FoxO proteins during cardiac hypertrophy. Atrogin-1, a protein that can block cardiac hypertrophy, may rely on the up-regulation of Foxo1 and Foxo3a to disrupt cardiac hypertrophy, since mice lacking atrogin-1 are susceptible to cardiac hypertrophy and do not yield increased expression of Foxo1 and Foxo3a[275]. In regards to smooth muscle cell growth, gene transfer of FoxO3a can inhibit neointimal hyperplasia through the prevention of vascular smooth muscle growth[276]. However, not all FoxO proteins may exert an inhibitory effect on vascular smooth muscle cells. FoxO4 may inhibit smooth muscle cell differentiation through the repression of the transcriptional coactivator of smooth muscle genes myocardin[277], but other work suggests that FoxO4 can also increase matrix metalloproteinase-9 expression to promote vascular smooth muscle migration and foster neointimal hyperplasia[278].

In consideration of the ability of FoxO proteins to regulate vascular smooth muscle cell proliferation, these transcription factors may have a significant clinical role in regards to disorders that involve hypertension and cardiac failure. Vascular smooth muscle cells are vital for the regulation of vascular tone and systemic arterial blood pressure. High flow states in vessels can reduce FoxO1 activity, resulting in the potential proliferation of vascular smooth muscle cells, vascular neointimal hyperplasia, and subsequent pathological states, such as hypertension[279]. Furthermore, $\alpha 1$-adrenergic agonists that increase systemic blood pressure can have the reverse effect and stimulate the expression of FoxO1 and its nuclear translocation that ultimately may lead to apoptotic EC injury[280]. More than moderate levels of vessel cyclic stretch that can occur during hypertension may lead to the phosphorylation and inhibition of Foxo1 and Foxo3a in smooth muscle cells to further contribute to pathological smooth muscle cell proliferation[281]. In human as well as murine models of cardiac failure, increased expression of Fox transcription factors, such as FoxO1a, have also been observed to suggest a potential association of FoxO proteins with imminent cardiac failure[282].

\section{EPO, FOXOS, CELL SURVIVAL, AND THE IMMUNE SYSTEM}

During a number of scenarios, EPO and FoxO proteins directly govern cell survival. With EPO, it can prevent cell injury during hypoxia[46,112,283,284,285,286], excitotoxicity[287,288,289], parasitic disease[290,291,292], endotoxin shock[293,294], free radical exposure[51,67,288], cardiac disease[295,296], A $\beta$ toxicity[192,297,298], pancreatic disease[299], and pulmonary disease[300,301]. EPO also represents a potential option for the prevention of retinal degeneration or neovascularization[302,303,304,305], as well as glaucoma[306]. Systemic application of EPO can also 
improve functional outcome and reduce cell loss during spinal cord injury[307,308], traumatic cerebral edema[309], cortical trauma[310], and epileptic activity[114,311,312].

In contrast to EPO cytoprotection, FoxO transcription factors more often lead to apoptosis during oxidative stress[3] (Fig.2). For example, forkhead transcription factors such as FoxO1 and FoxO3a must be present for oxidative stress to result in apoptotic cell injury[313]. FoxO3a in conjunction with JNK has also been shown to modulate an apoptotic ligand activating a Fas-mediated death pathway in cultured motoneurons[314], to lead to apoptosis through tumor-necrosis-factor-related apoptosis-inducing ligand (TRAIL) and BH3-only proteins Noxa and Bim in neuroblastoma cells[201], and to promote proapoptotic activity of p53[315]. In addition, loss of FoxO expression during oxidative stress is protective to cells. Protein inhibition or gene knockdown of FoxO1 or FoxO3a can lead to reduction in ischemic infarct size in the brain[316]. Removal of FoxO expression can also mediate protection of metabotropic glutamate receptors during vascular injury[199], enhance pancreatic $\beta$-cell or neuronal survival through $\mathrm{NAD}^{+}$ precursors during oxidative stress[200], and provide trophic factor protection with EPO[113] and neurotrophins[317].

Interestingly, FoxOs are associated with neurodegenerative pathways such as Alzheimer's disease. The National Institute on Aging estimates that almost 5 million people have Alzheimer's disease in the U.S. Furthermore, more than 24 million people suffer from AD, presenile dementia, and other disorders of cognitive loss worldwide. In Alzheimer's disease[318], A $\beta$ is toxic to cells[49,192,319,320,321] and can lead to oxidative stress[1,23,24]. A $\beta$ is also associated with the phosphorylation of FoxO1 and FoxO3a that can be blocked with ROS scavengers[322]. A common denominator in the pathways linked to $A \beta$ toxicity involves Wnt signaling[49,323] and $\beta$-catenin. The canonical Wnt pathway[324,325] involves $\beta$-catenin[45,226] and ties FoxO proteins and Wnt signaling together[36]. $\beta$-Catenin may increase FoxO transcriptional activity and competitively limit $\beta$-catenin interaction with members of the lymphoid enhancer factor/T-cell factor family[326]. This may lead to cell injury, since $\beta$-catenin has been demonstrated to be necessary for protection against $A \beta$ toxicity in neuronal cells[49]. However, not all conditions with FoxOs may lead to cell injury. Some studies suggest that the loss of FoxO1, FoxO3a, and FoxO4 protein expression may actually lead to an increase in free radical release that can be responsible for oxidative stress[267]. Furthermore, FoxO proteins may be protective during aging and exercise, since FoxO3a activity may enhance vascular smooth muscle antioxidant properties in aged animals and be beneficial to the cardiovascular system during physical exertion[327].

Given the significant roles that EPO and FoxOs play during cell survival, which is tightly linked to the immune system and allergic disorders[83,328], it may come as no surprise that these proteins are closely associated with modulation of the immune system, not only in the brain, but also throughout the body (Figs. 1 and 2). For example, in the brain, microglia lead to the phagocytic removal of both neurons and vascular cells[30,32,39]. During inflammation, microglial cells require the activation of intracellular cytoprotective pathways[31,40] in order to proliferate and remove injured cells[43,329]. Microglia can also form a barrier for the removal of foreign microorganisms from the central nervous system, and promote tissue repair during neuronal and vascular cell injury[31,330]. Yet, microglia may lead to cell injury through the generation of ROS[69,331] and through the production of cytokines[332,333].

EPO can reduce cytokine gene expression in ECs exposed to tumor necrosis factor[222], prevent ulcer progression in cases of scleroderma[334], modulate inflammation during experimental autoimmune encephalomyelitis[335], reduce inflammation in murine arthritis models[336], and block primary microglial activation and proliferation during oxidative stress[46,192] to prevent phagocytosis of injured cells through pathways that involve cellular membrane PS exposure, Akt[30], and the regulation of caspases[46,67,337]. EPO can directly inhibit several proinflammatory cytokines, such as IL-6, TNF- $\alpha$, and monocyte chemoattractant protein 1[80,338], and reduce leukocyte inflammation[339]. EPO may also foster the preservation of microglial cells for neuronal and vascular restructuring by preventing apoptotic injury in microglia[40,340].

In general, forkhead transcription factors also have an important role in maintaining immune system function. The forkhead family member FoxP3 can control the development and function of thymic- 
derived CD4(+)CD25(+) regulatory T cells (Treg) that impart autoimmunity. Loss of FoxP3 can result in autoimmune disorders[341]. Additional studies demonstrate the expression of FoxP3 in tumor cells, such as melanoma[342], as well as in Tregs that may significantly affect patient mortality, since the increased presence of Tregs in cancer patients combined with FoxP3 expression in tumors may impair antitumor autoimmune responses and lead to high mortality[343].

In regards to FoxO proteins, these transcription factors may also influence early apoptotic membrane PS externalization. The ability to regulate early apoptotic membrane PS exposure[46] and inflammatory cell activity[32] can ultimately affect cell survival, since activated immune cells can lead to the phagocytic removal of injured cells or tumor cells[39,63]. Recent work suggests a relationship between the regulation of immune system activity and the induction of apoptotic pathways that are dependent on FoxO proteins. Prevention of inflammatory activation and apoptosis in the nervous system, such as in systemic lupus erythematosus in animal models, may require the up-regulation of different Fox proteins, such as FoxJ1 and FoxO3a, that can block NF- $\mathrm{KB}$ activation and interferon- $\gamma$ secretion[344]. FoxO proteins may also work in concert with Fas signaling to clear activated $\mathrm{T}$ cells following a decrease in cytokine stimulation in patients with autoimmune lymphoproliferative syndromes[345], suggesting that activation of specific FoxO proteins may be beneficial for autoimmune disorders, but may impair treatments designed to target tumor cells through immune mediated pathways. Furthermore, in mice deficient for Foxo3a, lymphoproliferation, organ inflammation of the salivary glands, lung, and kidney, and increased activity of helper $\mathrm{T}$ cells result, supporting an important role for FoxO3a in preventing Tcell hyperactivity[346]. FoxO3a also appears to be necessary for neutrophil activity, since Foxo3a-null mice are resistant to models of neutrophilic inflammation that involve immune complex-mediated inflammatory arthritis[347]. Patients with rheumatoid arthritis and osteoarthritis show phosphorylation of FOXO3a in T lymphocytes as well as FOXO1 and FOXO4 in synovial macrophages, suggesting that loss of functional FOXO family members may lead to inflammatory cell activation in these disorders[348]. FOXO1 gene transcript levels also are down-regulated in peripheral blood mononuclear cells of patients with systemic lupus erythematosus and rheumatoid arthritis[349], illustrating a potential etiology through the loss of functional FOXO proteins for these disorders and possibly providing a biomarker of disease activity. Other studies show that FOXO1 protein controls L-selectin expression that can regulate human T-lymphocyte trafficking[350].

\section{THERAPEUTIC CONSIDERATIONS FOR CANCER}

The potential for the initiation or progression of cancer during EPO administration supports investigations that can elucidate the downstream mechanisms of this growth factor and cytokine in order to avoid unwanted clinical outcomes. In particular, the close association that EPO holds with FoxO proteins suggests potential avenues to limit or block tumor cell proliferation. FoxO proteins can control tumor growth through the induction of apoptosis and the blockade of cell cycle progression (Fig. 2). For example, FoxO3a and FoxO4 can promote cell cycle arrest in mouse myoblastic cell lines through modulation of growth-arrest and DNA-damage-response protein 45[78,81]. Treatment of chronic myelogenous leukemia cell lines with the Bcr-Abl tyrosine kinase inhibitor imatinib requires FoxO3a activation to antagonize cell proliferation and promote apoptotic cell death through increased TRAIL production[351]. In addition, the transcription factor E2F-1, which controls the induction of the cell cycle, has been reported in cell lines to increase the endogenous expression of FoxO1 and FoxO3a to lead to cell cycle arrest[352]. In contrast, the loss of FoxO3a activity in association with c-Myc, p27, and nuclear factor- $\kappa \mathrm{B}(\mathrm{NF}-\mathrm{\kappa B})$ can result in cell cycle induction and malignant transformation of mouse cells in the presence of oncogene activation[81,158]. Other work suggests that FoxO proteins utilize the p53 upstream regulator p19(Arf) through Myc to block cell cycle induction and lymphoma progression[353].

Studies with prostate cancer have shown that the tumor suppressor phosphatase and tensin homolog deleted on chromosome ten (PTEN) is mutated in approximately $80 \%$ of tumors with the loss of FOXO1 and FOXO3a activity. In cell cultures, overexpression of FoxO1 and FoxO3a in prostrate tumor cell lines 
also leads to apoptosis, suggesting that FoxO1 and FoxO3a are necessary for limiting prostate cell tumor growth[167]. Inhibition of FoxO3a activity can result in enhanced prostate tumor cell growth[354], while agents that increase FoxO3a activity in both androgen-sensitive and androgen-insensitive prostate cell lines prevent prostate cancer cell progression[355]. Therapeutic strategies that rely on the overexpression of a nonphosphorylatable form of FoxO3a that cannot be inactivated can also sensitize prostate cancer cells to androgen withdrawal-induced apoptosis[356]. However, in prostate cell lines, FoxO3a can be a positive regulator of androgen receptor expression and therefore may play a complex role in prostate cancer cell proliferation and growth inhibition[357]. Other factors that control FoxO protein function may also play a role during prostate tumor progression. In prostate cancer cells, cyclin-dependent kinase 1 (CDK1) can become overexpressed and subsequently phosphorylate FOXO1 to block its transcriptional activity and contribute to prostate tumorigenesis[358]. In a similar manner, it has been shown that astrocyte-elevated gene-1 (AEG-1) can be up-regulated in clinical prostate cancer[359], possibly leading to activation of Akt that suppresses FOXO3a[360] and apoptosis in prostate tumor cells.

Initial investigations of FOXO3a in clinical breast cancer suggested that activation of FOXO3a was associated with lymph nodal metastasis and a poor prognosis[361]. In contrast to these observations, other work has shown that FOXO3a was inactivated by IKK and that inactivation of FOXO3a was associated with a poor prognosis in breast cancer[362], suggesting that FOXO3a subcellular localization and pathways that enhance its activity could be used not only as a biomarker assay, but also as therapeutic targets. Other work in breast cancer cells demonstrated the tumor repressive ability of FoxOs by illustrating that increased activity of FoxO3a in association with JNK in breast cancer cell lines[363] or in association with cyclin-dependent kinase inhibitor p27 in isolated human breast cancer cells can prevent breast cancer growth[364]. In addition, FoxO proteins may be able to modulate estrogen function and indirectly block breast cancer growth. Overexpression of FoxO3a in breast cancer cell lines can decrease the expression of estrogen receptor-regulated genes and inhibits $17 \beta$-estradiol (E2)-dependent breast cancer growth[365].

FoxO proteins may also represent a viable option to control tumor progression in other tissues. FoxO proteins can function as redundant repressors of tumor growth. For example, somatic deletion in mice of Foxol, Foxo3a, and Foxo4 results in the growth of thymic lymphomas and hemangiomas[366]. Other work illustrates that FoxO3a activation in colon carcinoma cell lines prevents tumor proliferation through Myc target genes that involve the Mad/Mxd family of transcriptional repressors[367]. In addition, the loss of FoxO3a activity may participate in oncogenic transformation in B-chronic lymphocytic leukemia[368] and in the progression of chronic myelogenous leukemia cell lines[351]. Furthermore, studies suggest that some proteins, such as the Kaposi's sarcoma-associated herpes virus latent protein LANA2, may specifically block the transcriptional activity of FoxO3a to lead to tumor growth[369]. In cell models of endometrial cancer, presensitization of cells to block Akt activation and foster transcription activity of FoxO1 enhances the effect of chemotherapy to limit tumor growth[370].

\section{CONCLUSIONS AND CONSIDERATIONS}

Both EPO and FoxO transcription factors hold great potential to yield new strategies for the treatment of neurovascular injury, immune mediated diseases, metabolic disease, and cancer-related disorders, as well as to offer the ability to follow disease onset and progression as biomarkers. In reference to EPO, U.S. annual sale revenues for EPO have recently been reported to approach 9 billion dollars[371] and over 100 trials with the National Institutes of Health website (www.clinicaltrials.gov) presently exist that are either recruiting or in preparation to examine the role of EPO in patients with a variety of disorders that include anemia, cancer, cardiac ischemia, or spinal cord trauma. Although some cardiac injury studies do not always demonstrate a benefit with EPO[372,373], early studies in patients with anemia or who are on chronic hemodialysis have suggested a direct cardiac benefit from EPO administration[374,375]. In addition, EPO administration can improve exercise tolerance either during cardiac or renal insufficiency in patients with anemia and congestive heart failure[128,376], and that may be dependent on improved 
pulmonary function[377]. Furthermore, a randomized, concealed, multicenter trial of 1460 patients who received 40,000 $\mathrm{U}$ of epoetin alfa up to a 3-week maximum following intensive care unit admission for trauma demonstrated a reduced mortality[378].

Yet, EPO is not well tolerated with comorbid conditions such as congestive heart failure, hypertension[379], and neoplasms[143]. Some studies suggest that elevated plasma levels of EPO independent of hemoglobin concentration can be associated with increased severity of disease in individuals with congestive heart failure[380] and that EPO may contribute to vascular stenosis with intima hyperplasia[381]. Adverse effects during treatment with EPO are not uncommon, such as an increased incidence of thrombotic vascular effects[378] or the use of EPO in cancer patients receiving chemotherapy that has been associated with nonfatal myocardial infarction, pyrexia, vomiting, shortness of breath, paresthesias, and upper respiratory tract infection[382]. In addition, both acute and long-term administration of EPO can significantly elevate mean arterial pressure that may place patients with hypertension at risk[383].

Cancer progression has been another significant concern raised with EPO administration[84,384]. EPO and its receptor can be found in tumor specimens, may block tumor cell apoptosis through Akt[385], enhance metastatic disease[386], and complicate radiotherapy by assisting with tumor angiogenesis[387]. The potential for EPO to lead to neoplastic growth is not well defined or understood at this time[388]. A number of competing factors must be considered and weighed that include the possible benefits of EPO administration in patients with cancer, the synergistic effects of EPO with chemotherapeutic modalities[389,390], the potential protection against chemotherapy tissue injury[391], and the treatment of cancer-related anemia.

Additional considerations for EPO exist other than those associated with EPO abuse and gene doping[392,393,394]. EPO has been correlated with the alteration of red cell membrane properties, leading to a cognitive decrement in rodent animal models[80,95,338]. Development of potentially detrimental side effects during EPO therapy, such as for cerebral ischemia with increased metabolic rate and blood viscosity[395], could also severely limit the use of EPO. As a result, alternate strategies have been suggested. New proposals examine the role of targeted bioavailability for EPO, such as in bone marrow stromal cells genetically engineered to secrete EPO[396] and controlled release of EPO from encapsulated cells[397,398]. The passage of EPO entry into the central nervous system continues to attract significant interest[399] as well as does the use of novel intranasal routes for EPO administration[286]. The development of derivations of EPO to reduce erythropoietic activity and the potential associated vascular complications[287] have also been put forth as new directions for treatment. Yet these lines of investigation are not without limitations, since chemical derivatives of EPO can become absent of clinical efficacy[80,95] as well as possibly lose the ability to promote sustainable cytoprotective effects, such as neurogenesis[400] and angiogenesis[255,256,258,401].

In contrast to the concerns of EPO to promote cancer, FoxO proteins offer the potential to target and prevent neoplastic progression. The ability of FoxO proteins to control cell cycle progression and promote apoptosis supports the premise that FoxOs may be an important component for new strategies directed against tumorigenesis. For example, the use of triple mutant FoxO1 or FoxO3a expression in which three phosphorylation sites have been altered to prevent inactivation of this protein has been proposed to block melanoma tumors[202] and endometrial cancer[402]. Other work also offers additional support for the use of FoxO proteins as biomarkers of cancer growth. Down-regulation of the phosphatidylinositol 3 kinase and Akt pathways have been associated with increased transcript levels for FOXO1a and FOXO3a in clinical prostate cancer samples and may indicate the onset of precancerous changes or the progression of ongoing tumor growth[403]. Although loss of Akt activity in prostate cancer cells can result in enhanced FoxO3a activity and subsequent apoptosis of tumor cells[359], it is conceivable that early stages of cancer may lead to reduced Akt activity with insufficient levels of active forkhead transcription factors to limit tumor progression. In addition, the early and persistent expression of phosphorylated FOXO1a in gastric tumors may not only indicate the onset of cancer, but may also suggest an improved prognosis for patients[404]. 
The known mutations in FoxO proteins that exist in several disease entities may provide novel insights for the treatment of other disorders. Future analysis in larger populations of patients with premature ovarian failure and diabetes could strengthen our understanding of the role of FoxO proteins in these disorders. In addition, targeting the activity of FoxO1, FoxO3a, or FoxO4 in cardiac and endothelial cells may prevent the onset of pathological cardiac hypertrophy and neointimal hyperplasia that may result in atherosclerosis. Recent studies also suggest that the utilization and combination of multiple biomarkers may improve risk assessment for patients suffering from cardiovascular disorders[405]. These studies illustrate that FoxO proteins may serve as biomarkers of disease activity, such as in individuals with imminent cardiac failure[282].

However, similar to studies with EPO, FoxO transcription factors may have complex and sometimes detrimental clinical outcomes. For example, FoxO protein inhibition of cell cycle progression may not consistently lead to apoptotic cell death. Some investigations suggest that during oxidative stress, FoxO3a activation in association with Sirt1 can lead to cell cycle arrest, but not result in apoptotic cell injury[406]. Furthermore, during hypoxic stress, forkhead transcription factors, such as FOXO3a, may potentiate antiapoptotic pathways in breast cancer cells to further tumor growth[407]. FoxO proteins also have been linked to potential chemotherapy drug resistance with increased expression of MDR1 (P-glycoprotein) that has been associated with chemotherapy drug resistance in breast cancer cells. FoxO1 can stimulate the transcriptional activity of MDR1 that may promote increased tolerance of tumor cells[408]. In addition, the common pathways shared between Wnt and forkhead proteins may lead to other outcomes that alter the ability to control tumor growth[45,409]. FoxO proteins may assist with $\beta$-catenin activation in the Wnt pathway and lead to tumor cell proliferation[226]. In the presence of Wnt deregulation and increased $\beta$-catenin activity, tumorigenesis may ensue, such as with the proliferation of medulloblastoma tumors[252]. Therefore, the role of FoxO protein involvement in several disorders may not be consistently known and may be influenced by multiple parameters, such as tissue characteristics, cellular metabolic state, and the age of an individual.

\section{ACKNOWLEDGMENTS}

This research was supported by the following grants (KM): American Diabetes Association, American Heart Association (National), Bugher Foundation Award, Janssen Neuroscience Award, LEARN Foundation Award, MI Life Sciences Challenge Award, Nelson Foundation Award, NIH NIEHS (P30 ES06639), NIH NIA, and NIH NINDS.

\section{REFERENCES}

1. Chong, Z.Z., Li, F., and Maiese, K. (2005) Oxidative stress in the brain: novel cellular targets that govern survival during neurodegenerative disease. Prog. Neurobiol. 75, 207-246.

2. Maiese, K. (2008) Triple play: promoting neurovascular longevity with nicotinamide, WNT, and erythropoietin in diabetes mellitus. Biomed. Pharmacother. 62, 218-232.

3. Maiese, K., Chong, Z.Z., Hou, J., and Shang, Y.C. (2008) Erythropoietin and oxidative stress. Curr. Neurovasc. Res. 5, 125-142.

4. Regulska, M., Leskiewicz, M., Budziszewska, B., Kutner, A., Jantas, D., Basta-Kaim, A., Kubera, M., Jaworska-Feil, L., and Lason, W. (2007) Inhibitory effects of 1,25-dihydroxyvitamin D(3) and its low-calcemic analogues on staurosporine-induced apoptosis. Pharmacol. Rep. 59, 393-401.

5. Chlopicki, S., Swies, J., Mogielnicki, A., Buczko, W., Bartus, M., Lomnicka, M., Adamus, J., and Gebicki, J. (2007) 1-Methylnicotinamide (MNA), a primary metabolite of nicotinamide, exerts anti-thrombotic activity mediated by a cyclooxygenase-2/prostacyclin pathway. Br. J. Pharmacol. 152, 230-239.

6. Chong, Z.Z., Lin, S.H., and Maiese, K. (2002) Nicotinamide modulates mitochondrial membrane potential and cysteine protease activity during cerebral vascular endothelial cell injury. J. Vasc. Res. 39, 131-147.

7. Feng, Y., Paul, I.A., and LeBlanc, M.H. (2006) Nicotinamide reduces hypoxic ischemic brain injury in the newborn rat. Brain Res. Bull. 69, 117-122. 
8. Hara, N., Yamada, K., Shibata, T., Osago, H., Hashimoto, T., and Tsuchiya, M. (2007) Elevation of cellular NAD levels by nicotinic acid and involvement of nicotinic acid phosphoribosyltransferase in human cells. J. Biol. Chem. 282, 24574-24582.

9. Ieraci, A. and Herrera, D.G. (2006) Nicotinamide protects against ethanol-induced apoptotic neurodegeneration in the developing mouse brain. PLoS Med. 3, e101.

10. Lin, S.H., Vincent, A., Shaw, T., Maynard, K.I., and Maiese, K. (2000) Prevention of nitric oxide-induced neuronal injury through the modulation of independent pathways of programmed cell death. J. Cereb. Blood Flow Metab. 20 , 1380-1391.

11. Maiese, K. and Chong, Z.Z. (2003) Nicotinamide: necessary nutrient emerges as a novel cytoprotectant for the brain. Trends Pharmacol. Sci. 24, 228-232.

12. Pearl, R. (1928) The Rate of Living. University of London Press, London.

13. Muller, F.L., Lustgarten, M.S., Jang, Y., Richardson, A., and Van Remmen, H. (2007) Trends in oxidative aging theories. Free Radic. Biol. Med. 43, 477-503.

14. Yui, R. and Matsuura, E.T. (2006) Detection of deletions flanked by short direct repeats in mitochondrial DNA of aging Drosophila. Mutat. Res. 594, 155-161.

15. Chong, Z.Z., Li, F., and Maiese, K. (2006) Attempted cell cycle induction in post-mitotic neurons occurs in early and late apoptotic programs through Rb, E2F1, and caspase 3. Curr. Neurovasc. Res. 3, 25-39.

16. De Felice, F.G., Velasco, P.T., Lambert, M.P., Viola, K., Fernandez, S.J., Ferreira, S.T., and Klein, W.L. (2007) Abeta oligomers induce neuronal oxidative stress through an N-methyl-D-aspartate receptor-dependent mechanism that is blocked by the Alzheimer drug memantine. J. Biol. Chem. 282, 11590-11601.

17. Lin, S.H. and Maiese, K. (2001) The metabotropic glutamate receptor system protects against ischemic free radical programmed cell death in rat brain endothelial cells. J. Cereb. Blood Flow Metab. 21, 262-275.

18. Lee, S.J., Cho, K.S., and Koh, J.Y. (2009) Oxidative injury triggers autophagy in astrocytes: the role of endogenous zinc. Glia 57, 1351-1361.

19. Cohen, S.M., Cordeiro-Stone, M., and Kaufman, D.G. (2007) Early replication and the apoptotic pathway. J. Cell. Physiol. 213, 434-439.

20. He, X.L., Wang, Y.H., Gao, M., Li, X.X., Zhang, T.T., and Du, G.H. (2009) Baicalein protects rat brain mitochondria against chronic cerebral hypoperfusion-induced oxidative damage. Brain Res. 1249, 212-221.

21. Maiese, K., Chong, Z.Z., Shang, Y.C., and Hou, J. (2008) Therapeutic promise and principles: metabotropic glutamate receptors. Oxid. Med. Cell. Longev. 1, 1-14.

22. Plecita-Hlavata, L., Lessard, M., Santorova, J., Bewersdorf, J., and Jezek, P. (2008) Mitochondrial oxidative phosphorylation and energetic status are reflected by morphology of mitochondrial network in INS-1E and HEP-G2 cells viewed by 4Pi microscopy. Biochim. Biophys. Acta 1777, 834-846.

23. Chong, Z.Z., Li, F., and Maiese, K. (2005) Stress in the brain: novel cellular mechanisms of injury linked to Alzheimer's disease. Brain Res. Brain Res. Rev. 49, 1-21.

24. Guglielmotto, M., Tamagno, E., and Danni, O. (2009) Oxidative stress and hypoxia contribute to Alzheimer's disease pathogenesis: two sides of the same coin. TheScientificWorldJOURNAL 9, 781-791.

25. Soo, E.T., Ng, Y.K., Bay, B.H., and Yip, G.W. (2008) Heat shock proteins and neurodegenerative disorders. TheScientificWorldJOURNAL 8, 270-274.

26. Nagley, P., Higgins, G.C., Atkin, J.D., and Beart, P.M. (2009) Multifaceted deaths orchestrated by mitochondria in neurones. Biochim. Biophys. Acta [Epub ahead of print]

27. Harris, S.E., Fox, H., Wright, A.F., Hayward, C., Starr, J.M., Whalley, L.J., and Deary, I.J. (2007) A genetic association analysis of cognitive ability and cognitive ageing using 325 markers for 109 genes associated with oxidative stress or cognition. BMC Genet. 8, 43.

28. Leuner, K., Hauptmann, S., Abdel-Kader, R., Scherping, I., Keil, U., Strosznajder, J.B., Eckert, A., and Muller, W.E. (2007) Mitochondrial dysfunction: the first domino in brain aging and Alzheimer's disease? Antioxid. Redox Signal. 9, 1659-1675.

29. Okouchi, M., Ekshyyan, O., Maracine, M., and Aw, T.Y. (2007) Neuronal apoptosis in neurodegeneration. Antioxid. Redox Signal. 9, 1059-1096.

30. Chong, Z.Z., Kang, J.Q., and Maiese, K. (2004) Akt1 drives endothelial cell membrane asymmetry and microglial activation through Bcl-x(L) and caspase 1, 3, and 9. Exp. Cell Res. 296, 196-207.

31. Chong, Z.Z., Li, F., and Maiese, K. (2007) The pro-survival pathways of mTOR and protein kinase B target glycogen synthase kinase-3beta and nuclear factor-kappaB to foster endogenous microglial cell protection. Int. J. Mol. Med. 19, 263-272.

32. Kang, J.Q., Chong, Z.Z., and Maiese, K. (2003) Critical role for Akt1 in the modulation of apoptotic phosphatidylserine exposure and microglial activation. Mol. Pharmacol. 64, 557-569.

33. Karunakaran, S., Diwakar, L., Saeed, U., Agarwal, V., Ramakrishnan, S., Iyengar, S., and Ravindranath, V. (2007) Activation of apoptosis signal regulating kinase 1 (ASK1) and translocation of death-associated protein, Daxx, in substantia nigra pars compacta in a mouse model of Parkinson's disease: protection by alpha-lipoic acid. FASEB J. 21, 2226-2236.

34. Verdaguer, E., Susana Gde, A., Clemens, A., Pallas, M., and Camins, A. (2007) Implication of the transcription factor E2F-1 in the modulation of neuronal apoptosis. Biomed. Pharmacother. 61, 390-399. 
35. Chong, Z.Z., Li, F., and Maiese, K. (2005) Employing new cellular therapeutic targets for Alzheimer's disease: a change for the better? Curr. Neurovasc. Res. 2, 55-72.

36. Maiese, K., Chong, Z.Z., Shang, Y.C., and Hou, J. (2008) Rogue proliferation versus restorative protection: where do we draw the line for Wnt and forkhead signaling? Expert Opin. Ther. Targets 12, 905-916.

37. Maiese, K., Vincent, A., Lin, S.H., and Shaw, T. (2000) Group I and Group III metabotropic glutamate receptor subtypes provide enhanced neuroprotection. J. Neurosci. Res. 62, 257-272.

38. Mari, C., Karabiyikoglu, M., Goris, M.L., Tait, J.F., Yenari, M.A., and Blankenberg, F.G. (2004) Detection of focal hypoxic-ischemic injury and neuronal stress in a rodent model of unilateral MCA occlusion/reperfusion using radiolabeled annexin V. Eur. J. Nucl. Med. Mol. Imaging 31, 733-739.

39. Chong, Z.Z., Kang, J., Li, F., and Maiese, K. (2005) mGluRI targets microglial activation and selectively prevents neuronal cell engulfment through Akt and caspase dependent pathways. Curr. Neurovasc. Res. 2, 197-211.

40. Li, F., Chong, Z.Z., and Maiese, K. (2006) Microglial integrity is maintained by erythropoietin through integration of Akt and its substrates of glycogen synthase kinase-3beta, beta-catenin, and nuclear factor-kappaB. Curr. Neurovasc. Res. 3, 187-201.

41. Chong, Z.Z., Kang, J.Q., and Maiese, K. (2003) Metabotropic glutamate receptors promote neuronal and vascular plasticity through novel intracellular pathways. Histol. Histopathol. 18, 173-189.

42. Kang, J.Q., Chong, Z.Z., and Maiese, K. (2003) Akt1 protects against inflammatory microglial activation through maintenance of membrane asymmetry and modulation of cysteine protease activity. J. Neurosci. Res. 74, 37-51.

43. Mallat, M., Marin-Teva, J.L., and Cheret, C. (2005) Phagocytosis in the developing CNS: more than clearing the corpses. Curr. Opin. Neurobiol. 15, 101-107.

44. Li, F., Chong, Z.Z., and Maiese, K. (2006) Cell life versus cell longevity: the mysteries surrounding the NAD(+) precursor nicotinamide. Curr. Med. Chem. 13, 883-895.

45. Li, F., Chong, Z.Z., and Maiese, K. (2006) Winding through the WNT pathway during cellular development and demise. Histol. Histopathol. 21, 103-124.

46. Chong, Z.Z., Kang, J.Q., and Maiese, K. (2003) Erythropoietin fosters both intrinsic and extrinsic neuronal protection through modulation of microglia, Akt1, Bad, and caspase-mediated pathways. Br. J. Pharmacol. 138, 1107-1118.

47. Maiese, K., Ahmad, I., TenBroeke, M., and Gallant, J. (1999) Metabotropic glutamate receptor subtypes independently modulate neuronal intracellular calcium. J. Neurosci. Res. 55, 472-485.

48. Vincent, A.M. and Maiese, K. (1999) Direct temporal analysis of apoptosis induction in living adherent neurons. $J$. Histochem. Cytochem. 47, 661-672.

49. Chong, Z.Z., Li, F., and Maiese, K. (2007) Cellular demise and inflammatory microglial activation during betaamyloid toxicity are governed by Wnt1 and canonical signaling pathways. Cell Signal. 19, 1150-1162.

50. Shang, Y.C., Chong, Z.Z., Hou, J., and Maiese, K. (2009) The forkhead transcription factor FoxO3a controls microglial inflammatory activation and eventual apoptotic injury through caspase 3. Curr. Neurovasc. Res. 6, $20-31$.

51. Chong, Z.Z., Lin, S.H., Kang, J.Q., and Maiese, K. (2003) Erythropoietin prevents early and late neuronal demise through modulation of Akt1 and induction of caspase 1, 3, and 8. J. Neurosci. Res. 71, 659-669.

52. Chong, Z.Z., Lin, S.H., Kang, J.Q., and Maiese, K. (2003) The tyrosine phosphatase SHP2 modulates MAP kinase p38 and caspase 1 and 3 to foster neuronal survival. Cell. Mol. Neurobiol. 23, 561-578.

53. Maiese, K. and Boccone, L. (1995) Neuroprotection by peptide growth factors against anoxia and nitric oxide toxicity requires modulation of protein kinase C. J. Cereb. Blood Flow Metab. 15, 440-449.

54. Maiese, K., Boniece, I.R., Skurat, K., and Wagner, J.A. (1993) Protein kinases modulate the sensitivity of hippocampal neurons to nitric oxide toxicity and anoxia. J. Neurosci. Res. 36, 77-87.

55. Maiese, K., TenBroeke, M., and Kue, I. (1997) Neuroprotection of lubeluzole is mediated through the signal transduction pathways of nitric oxide. J. Neurochem. 68, 710-714.

56. Salinas, M., Diaz, R., Abraham, N.G., Ruiz de Galarreta, C.M., and Cuadrado, A. (2003) Nerve growth factor protects against 6-hydroxydopamine-induced oxidative stress by increasing expression of heme oxygenase-1 in a phosphatidylinositol 3-kinase-dependent manner. J. Biol. Chem. 278, 13898-13904.

57. Leytin, V., Allen, D.J., Mykhaylov, S., Lyubimov, E., and Freedman, J. (2006) Thrombin-triggered platelet apoptosis. J. Thromb. Haemost. 4, 2656-2663.

58. Maiese, K. and Vincent, A.M. (2000) Critical temporal modulation of neuronal programmed cell injury. Cell. Mol. Neurobiol. 20, 383-400.

59. Maiese, K. and Vincent, A.M. (2000) Membrane asymmetry and DNA degradation: functionally distinct determinants of neuronal programmed cell death. J. Neurosci. Res. 59, 568-580.

60. Chong, Z.Z., Kang, J.Q., and Maiese, K. (2004) Essential cellular regulatory elements of oxidative stress in early and late phases of apoptosis in the central nervous system. Antioxid. Redox Signal. 6, 277-287.

61. Dombroski, D., Balasubramanian, K., and Schroit, A.J. (2000) Phosphatidylserine expression on cell surfaces promotes antibody- dependent aggregation and thrombosis in beta2-glycoprotein I-immune mice. J. Autoimmun. 14, 221-229.

62. Jessel, R., Haertel, S., Socaciu, C., Tykhonova, S., and Diehl, H.A. (2002) Kinetics of apoptotic markers in exogeneously induced apoptosis of EL4 cells. J. Cell. Mol. Med. 6, 82-92.

63. Chong, Z.Z. and Maiese, K. (2007) The Src homology 2 domain tyrosine phosphatases SHP-1 and SHP-2: diversified control of cell growth, inflammation, and injury. Histol. Histopathol. 22, 1251-1267. 
64. Vincent, A.M. and Maiese, K. (1999) Nitric oxide induction of neuronal endonuclease activity in programmed cell death. Exp. Cell Res. 246, 290-300.

65. Vincent, A.M., TenBroeke, M., and Maiese, K. (1999) Metabotropic glutamate receptors prevent programmed cell death through the modulation of neuronal endonuclease activity and intracellular pH. Exp. Neurol. 155, 79-94.

66. Di Lisa, F., Menabo, R., Canton, M., Barile, M., and Bernardi, P. (2001) Opening of the mitochondrial permeability transition pore causes depletion of mitochondrial and cytosolic NAD+ and is a causative event in the death of myocytes in postischemic reperfusion of the heart. J. Biol. Chem. 276, 2571-2575.

67. Chong, Z.Z., Kang, J.Q., and Maiese, K. (2003) Apaf-1, Bcl-xL, cytochrome c, and caspase-9 form the critical elements for cerebral vascular protection by erythropoietin. J. Cereb. Blood Flow Metab. 23, 320-330.

68. Chong, Z.Z., Lin, S.H., Li, F., and Maiese, K. (2005) The sirtuin inhibitor nicotinamide enhances neuronal cell survival during acute anoxic injury through Akt, Bad, PARP, and mitochondrial associated "anti-apoptotic" pathways. Curr. Neurovasc. Res. 2, 271-285.

69. Maiese, K. and Chong, Z.Z. (2004) Insights into oxidative stress and potential novel therapeutic targets for Alzheimer disease. Restor. Neurol. Neurosci. 22, 87-104.

70. Li, F., Chong, Z.Z., and Maiese, K. (2004) Navigating novel mechanisms of cellular plasticity with the NAD+ precursor and nutrient nicotinamide. Front. Biosci. 9, 2500-2520.

71. Wilson, F.H., Hariri, A., Farhi, A., Zhao, H., Petersen, K.F., Toka, H.R., Nelson-Williams, C., Raja, K.M., Kashgarian, M., Shulman, G.I., Scheinman, S.J., and Lifton, R.P. (2004) A cluster of metabolic defects caused by mutation in a mitochondrial tRNA. Science 306, 1190-1194.

72. Roberts, E., Jr. and Chih, C.P. (1997) The influence of age of pH regulation in hippocampal slices before, during, and after anoxia. J. Cereb. Blood Flow Metab. 17, 560-566.

73. Cardella, F. (2005) Insulin therapy during diabetic ketoacidosis in children. Acta Biomed. 76(Suppl 3), 49-54.

74. Kratzsch, J., Knerr, I., Galler, A., Kapellen, T., Raile, K., Korner, A., Thiery, J., Dotsch, J., and Kiess, W. (2006) Metabolic decompensation in children with type 1 diabetes mellitus associated with increased serum levels of the soluble leptin receptor. Eur. J. Endocrinol. 155, 609-614.

75. Ito, N., Bartunek, J., Spitzer, K.W., and Lorell, B.H. (1997) Effects of the nitric oxide donor sodium nitroprusside on intracellular $\mathrm{pH}$ and contraction in hypertrophied myocytes. Circulation 95, 2303-2311.

76. Vincent, A.M., TenBroeke, M., and Maiese, K. (1999) Neuronal intracellular pH directly mediates nitric oxideinduced programmed cell death. J. Neurobiol. 40, 171-184.

77. Maiese, K. (2009) Marking the onset of oxidative stress: biomarkers and novel strategies. Oxid. Med. Cell. Longev. 2, 1.

78. Maiese, K., Chong, Z.Z., Li, F., and Shang, Y.C. (2008) Erythropoietin: elucidating new cellular targets that broaden therapeutic strategies. Prog. Neurobiol. 85, 194-213.

79. Maiese, K., Chong, Z.Z., and Shang, Y.C. (2008) Raves and risks for erythropoietin. Cytokine Growth Factor Rev. 19, 145-155.

80. Maiese, K., Li, F., and Chong, Z.Z. (2005) New avenues of exploration for erythropoietin. JAMA 293, 90-95.

81. Maiese, K., Chong, Z.Z., and Shang, Y.C. (2008) OutFOXOing disease and disability: the therapeutic potential of targeting FoxO proteins. Trends Mol. Med. 14, 219-227.

82. Maiese, K., Chong, Z.Z., Shang, Y.C., and Hou, J. (2009) FoxO proteins: cunning concepts and considerations for the cardiovascular system. Clin. Sci. (Lond.) 116, 191-203.

83. Maiese, K., Chong, Z.Z., Shang, Y.C., and Hou, J. (2009) A "FOXO" in sight: targeting Foxo proteins from conception to cancer. Med. Res. Rev. 29, 395-418.

84. Maiese, K., Li, F., and Chong, Z.Z. (2005) Erythropoietin and cancer. JAMA 293, 1858-1859.

85. Bloomer, R. and Fisher-Wellman, K. (2009) Systemic oxidative stress is increased to a greater degree in young, obese women following consumption of a high fat meal. Oxid. Med. Cell. Longev. 2, 19-25.

86. Fisher-Wellman, K., Bell, H., and Bloomer, R. (2009) Oxidative stress and antioxidant defense mechanisms linked to exercise during cardiopulmonary and metabolic disorders. Oxid. Med. Cell. Longev. 2, 43-51.

87. Carnot, P. and DeFlandre, C. (1906) Sur l'activite hemopoietique de serum au cours de la regeneration du sang. $C$. $R$. Acad. Sci. (Paris) 143, 384-386.

88. Fisher, J.W. (2003) Erythropoietin: physiology and pharmacology update. Exp. Biol. Med. (Maywood) 228, 1-14.

89. Erslev, A.J. (1974) In vitro production of erythropoietin by kidneys perfused with a serum-free solution. Blood $\mathbf{4 4}$, 77-85.

90. Gibelli, C. (1911) Uber den wert des serums anamisch gemachten tiere bei der regeneration des blutes. Arch. Exp. Pathol. Pharmacol. 65, 284-302.

91. Sandor, G. (1932) Uber die blutbidende wirkung des serums von tieren, die in verdunnter luft gehalten wuren. $Z$. Gesante Exp. Med. 82, 633-646.

92. Reissmann, K. (1950) Studies on the mechanism of erythropoietin stimulation in parabiotic rats during hypoxia. Blood 5, 347-380.

93. Jacobs, K., Shoemaker, C., Rudersdorf, R., Neill, S.D., Kaufman, R.J., Mufson, A., Seehra, J., Jones, S.S., Hewick, R., Fritsch, E.F., Kawakita, M., Shimizu, T., and Miyake, T. (1985) Isolation and characterization of genomic and cDNA clones of human erythropoietin. Nature 313, 806-810. 
94. Lin, F.K., Suggs, S., Lin, C.H., Browne, J.K., Smalling, R., Egrie, J.C., Chen, K.K., Fox, G.M., Martin, F., Stabinsky, Z., Badrawi, S., Lai, P.-H., and Goldwasser, E. (1985) Cloning and expression of the human erythropoietin gene. Proc. Natl. Acad. Sci. U. S. A. 82, 7580-7584.

95. Maiese, K., Li, F., and Chong, Z.Z. (2004) Erythropoietin in the brain: can the promise to protect be fulfilled? Trends Pharmacol. Sci. 25, 577-583.

96. Toyoda, T., Itai, T., Arakawa, T., Aoki, K.H., and Yamaguchi, H. (2000) Stabilization of human recombinant erythropoietin through interactions with the highly branched N-glycans. J. Biochem. (Tokyo) 128, 731-737.

97. Uchida, E., Morimoto, K., Kawasaki, N., Izaki, Y., Abdu Said, A., and Hayakawa, T. (1997) Effect of active oxygen radicals on protein and carbohydrate moieties of recombinant human erythropoietin. Free Radic. Res. 27, 311-323.

98. Tsuda, E., Goto, M., Murakami, A., Akai, K., Ueda, M., Kawanishi, G., Takahashi, N., Sasaki, R., Chiba, H., Ishihara, H., Mori, M., Tejima, S., Endo, S., and Arata, Y. (1988) Comparative structural study of N-linked oligosaccharides of urinary and recombinant erythropoietins. Biochemistry 27, 5646-5654.

99. Krantz, S.B. (1991) Erythropoietin. Blood 77, 419-434.

100. Tsuda, E., Kawanishi, G., Ueda, M., Masuda, S., and Sasaki, R. (1990) The role of carbohydrate in recombinant human erythropoietin. Eur. J. Biochem. 188, 405-411.

101. Fliser, D. and Haller, H. (2007) Erythropoietin and treatment of non-anemic conditions--cardiovascular protection. Semin. Hematol. 44, 212-217.

102. Lacombe, C., Da Silva, J.L., Bruneval, P., Casadevall, N., Camilleri, J.P., Bariety, J., Tambourin, P., and Varet, B. (1991) Erythropoietin: sites of synthesis and regulation of secretion. Am. J. Kidney Dis. 18, 14-19.

103. Mujais, S.K., Beru, N., Pullman, T.N., and Goldwasser, E. (1999) Erythropoietin is produced by tubular cells of the rat kidney. Cell Biochem. Biophys. 30, 153-166.

104. Chang, Y.K., Choi, D.E., Na, K.R., Lee, S.J., Suh, K.S., Kim, S.Y., Shin, Y.T., and Lee, K.W. (2009) Erythropoietin attenuates renal injury in an experimental model of rat unilateral ureteral obstruction via anti-inflammatory and antiapoptotic effects. J. Urol. 181, 1434-1443.

105. Sharples, E.J., Thiemermann, C., and Yaqoob, M.M. (2005) Mechanisms of disease: cell death in acute renal failure and emerging evidence for a protective role of erythropoietin. Nat. Clin. Pract. Nephrol. 1, 87-97.

106. Sharples, E.J. and Yaqoob, M.M. (2006) Erythropoietin in experimental acute renal failure. Nephron Exp. Nephrol. 104, e83-88.

107. Chong, Z.Z., Kang, J.Q., and Maiese, K. (2002) Angiogenesis and plasticity: role of erythropoietin in vascular systems. J. Hematother. Stem Cell Res. 11, 863-871.

108. Schmeding, M., Boas-Knoop, S., Lippert, S., Ruehl, M., Somasundaram, R., Dagdelen, T., Neuhaus, P., and Neumann, U.P. (2008) Erythropoietin promotes hepatic regeneration after extended liver resection in rats. $J$. Gastroenterol. Hepatol. 23, 1125-1131.

109. Schmeding, M., Neumann, U.P., Boas-Knoop, S., Spinelli, A., and Neuhaus, P. (2007) Erythropoietin reduces ischemia-reperfusion injury in the rat liver. Eur. Surg. Res. 39, 189-197.

110. Davis, L.E., Widness, J.A., and Brace, R.A. (2003) Renal and placental secretion of erythropoietin during anemia or hypoxia in the ovine fetus. Am. J. Obstet. Gynecol. 189, 1764-1770.

111. Teramo, K.A. and Widness, J.A. (2009) Increased fetal plasma and amniotic fluid erythropoietin concentrations: markers of intrauterine hypoxia. Neonatology 95, 105-116.

112. Chong, Z.Z., Kang, J.Q., and Maiese, K. (2002) Erythropoietin is a novel vascular protectant through activation of Akt1 and mitochondrial modulation of cysteine proteases. Circulation 106, 2973-2979.

113. Chong, Z.Z. and Maiese, K. (2007) Erythropoietin involves the phosphatidylinositol 3-kinase pathway, 14-3-3 protein and FOXO3a nuclear trafficking to preserve endothelial cell integrity. Br. J. Pharmacol. 150, 839-850.

114. Mikati, M.A., Hokayem, J.A., and Sabban, M.E. (2007) Effects of a single dose of erythropoietin on subsequent seizure susceptibility in rats exposed to acute hypoxia at p10. Epilepsia 48, 175-181.

115. Moon, C., Krawczyk, M., Paik, D., Coleman, T., Brines, M., Juhaszova, M., Sollott, S.J., Lakatta, E.G., and Talan, M.I. (2006) Erythropoietin, modified to not stimulate red blood cell production, retains its cardioprotective properties. J. Pharmacol. Exp. Ther. 316, 999-1005.

116. Um, M., Gross, A.W., and Lodish, H.F. (2007) A "classical" homodimeric erythropoietin receptor is essential for the antiapoptotic effects of erythropoietin on differentiated neuroblastoma SH-SY5Y and pheochromocytoma PC-12 cells. Cell. Signal. 19, 634-645.

117. Arcasoy, M.O. (2008) The non-haematopoietic biological effects of erythropoietin. Br. J. Haematol. 141, 14-31.

118. Schumann, C., Triantafilou, K., Krueger, S., Hombach, V., Triantafilou, M., Becher, G., and Lepper, P.M. (2006) Detection of erythropoietin in exhaled breath condensate of nonhypoxic subjects using a multiplex bead array. Mediators Inflamm. 2006, 18061.

119. Kaindl, A.M., Sifringer, M., Koppelstaetter, A., Genz, K., Loeber, R., Boerner, C., Stuwe, J., Klose, J., and Felderhoff-Mueser, U. (2008) Erythropoietin protects the developing brain from hyperoxia-induced cell death and proteome changes. Ann. Neurol. 64, 523-534.

120. Yis, U., Kurul, S.H., Kumral, A., Tugyan, K., Cilaker, S., Yilmaz, O., Genc, S., and Genc, K. (2008) Effect of erythropoietin on oxygen-induced brain injury in the newborn rat. Neurosci. Lett. 448, 245-249.

121. He, Z., Huang, L., Wu, Y., Wang, J., Wang, H., and Guo, L. (2008) DDPH: improving cognitive deficits beyond its alpha 1-adrenoceptor antagonism in chronic cerebral hypoperfused rats. Eur. J. Pharmacol. 588, 178-188. 
122. Berkingali, N., Warnecke, A., Gomes, P., Paasche, G., Tack, J., Lenarz, T., and Stover, T. (2008) Neurite outgrowth on cultured spiral ganglion neurons induced by erythropoietin. Hear. Res. 243, 121-126.

123. Shah, R.C., Wilson, R.S., Tang, Y., Dong, X., Murray, A., and Bennett, D.A. (2009) Relation of hemoglobin to level of cognitive function in older persons. Neuroepidemiology 32, 40-46.

124. Bierer, R., Peceny, M.C., Hartenberger, C.H., and Ohls, R.K. (2006) Erythropoietin concentrations and neurodevelopmental outcome in preterm infants. Pediatrics 118, e635-640.

125. Pillai, A., Dhandapani, K.M., Pillai, B.A., Terry, A.V., Jr., and Mahadik, S.P. (2008) Erythropoietin prevents haloperidol treatment-induced neuronal apoptosis through regulation of BDNF. Neuropsychopharmacology 33, 19421951.

126. McLeod, M., Hong, M., Mukhida, K., Sadi, D., Ulalia, R., and Mendez, I. (2006) Erythropoietin and GDNF enhance ventral mesencephalic fiber outgrowth and capillary proliferation following neural transplantation in a rodent model of Parkinson's disease. Eur. J. Neurosci. 24, 361-370.

127. Assaraf, M.I., Diaz, Z., Liberman, A., Miller, W.H., Jr., Arvanitakis, Z., Li, Y., Bennett, D.A., and Schipper, H.M. (2007) Brain erythropoietin receptor expression in Alzheimer disease and mild cognitive impairment. J. Neuropathol. Exp. Neurol. 66, 389-398.

128. Palazzuoli, A., Silverberg, D., Iovine, F., Capobianco, S., Giannotti, G., Calabro, A., Campagna, S.M., and Nuti, R. (2006) Erythropoietin improves anemia exercise tolerance and renal function and reduces B-type natriuretic peptide and hospitalization in patients with heart failure and anemia. Am. Heart J. 152, 1096.e9-15.

129. Palazzuoli, A., Silverberg, D.S., Iovine, F., Calabro, A., Campagna, M.S., Gallotta, M., and Nuti, R. (2007) Effects of beta-erythropoietin treatment on left ventricular remodeling, systolic function, and B-type natriuretic peptide levels in patients with the cardiorenal anemia syndrome. Am. Heart J. 154, 645.e9-15.

130. Smith, K., Semple, D., Bhandari, S., and Seymour, A.M. (2009) Cellular basis of uraemic cardiomyopathy: a role for erythropoietin? Eur. J. Heart Fail. 11, 732-738.

131. Gleissner, C.A., Klingenberg, R., Staritz, P., Koch, A., Ehlermann, P., Wiggenhauser, A., and Dengler, T.J. (2006) Role of erythropoietin in anemia after heart transplantation. Int. J. Cardiol. 112, 341-347.

132. Mocini, D., Leone, T., Tubaro, M., Santini, M., and Penco, M. (2007) Structure, production and function of erythropoietin: implications for therapeutical use in cardiovascular disease. Curr. Med. Chem. 14, 2278-2287.

133. Song, Y.R., Lee, T., You, S.J., Chin, H.J., Chae, D.W., Lim, C., Park, K.H., Han, S., Kim, J.H., and Na, K.Y. (2009) Prevention of acute kidney injury by erythropoietin in patients undergoing coronary artery bypass grafting: a pilot study. Am. J. Nephrol. 30, 253-260.

134. Digicaylioglu, M., Garden, G., Timberlake, S., Fletcher, L., and Lipton, S.A. (2004) Acute neuroprotective synergy of erythropoietin and insulin-like growth factor I. Proc. Natl. Acad. Sci. U. S. A. 101, 9855-9860.

135. Genc, S., Koroglu, T.F., and Genc, K. (2004) Erythropoietin as a novel neuroprotectant. Restor. Neurol. Neurosci. 22, $105-119$.

136. Anagnostou, A., Liu, Z., Steiner, M., Chin, K., Lee, E.S., Kessimian, N., and Noguchi, C.T. (1994) Erythropoietin receptor mRNA expression in human endothelial cells. Proc. Natl. Acad. Sci. U. S. A. 91, 3974-3978.

137. Ogilvie, M., Yu, X., Nicolas-Metral, V., Pulido, S.M., Liu, C., Ruegg, U.T., and Noguchi, C.T. (2000) Erythropoietin stimulates proliferation and interferes with differentiation of myoblasts. J. Biol. Chem. 275, 39754-39761.

138. Fenjves, E.S., Ochoa, M.S., Cabrera, O., Mendez, A.J., Kenyon, N.S., Inverardi, L., and Ricordi, C. (2003) Human, nonhuman primate, and rat pancreatic islets express erythropoietin receptors. Transplantation 75, 1356-1360.

139. Sanchez, P.E., Navarro, F.P., Fares, R.P., Nadam, J., Georges, B., Moulin, C., Le Cavorsin, M., Bonnet, C., Ryvlin, P., Belmeguenai, A., Bodennec, J., Morales, A., and Bezin, L. (2009) Erythropoietin receptor expression is concordant with erythropoietin but not with common beta chain expression in the rat brain throughout the life span. $J$. Comp. Neurol. 514, 403-414.

140. Hassan, K., Gross, B., Simri, W., Rubinchik, I., Cohen, H., Jacobi, J., Shasha, S.M., and Kristal, B. (2004) The presence of erythropoietin receptors in the human peripheral nervous system. Clin. Nephrol. 61, 127-129.

141. Chong, Z.Z., Kang, J.Q., and Maiese, K. (2002) Hematopoietic factor erythropoietin fosters neuroprotection through novel signal transduction cascades. J. Cereb. Blood Flow Metab. 22, 503-514.

142. Yamaji, R., Okada, T., Moriya, M., Naito, M., Tsuruo, T., Miyatake, K., and Nakano, Y. (1996) Brain capillary endothelial cells express two forms of erythropoietin receptor mRNA. Eur. J. Biochem. 239, 494-500.

143. Maiese, K., Chong, Z., and Li, F. (2009) Reducing oxidative stress and enhancing neurovascular longevity during diabetes mellitus. In Neurovascular Medicine: Pursuing Cellular Longevity for Healthy Aging. Maiese, K, Ed. Oxford University Press, New York. pp. 540-564.

144. Yasuda, Y., Masuda, S., Chikuma, M., Inoue, K., Nagao, M., and Sasaki, R. (1998) Estrogen-dependent production of erythropoietin in uterus and its implication in uterine angiogenesis. J. Biol. Chem. 273, 25381-25387.

145. Masuda, S., Kobayashi, T., Chikuma, M., Nagao, M., and Sasaki, R. (2000) The oviduct produces erythropoietin in an estrogen- and oxygen-dependent manner. Am. J. Physiol. Endocrinol. Metab. 278, E1038-1044.

146. Chikuma, M., Masuda, S., Kobayashi, T., Nagao, M., and Sasaki, R. (2000) Tissue-specific regulation of erythropoietin production in the murine kidney, brain, and uterus. Am. J. Physiol. Endocrinol. Metab. 279, E12421248. 
147. Obara, N., Imagawa, S., Nakano, Y., Suzuki, N., Yamamoto, M., and Nagasawa, T. (2003) Suppression of erythropoietin gene expression by cadmium depends on inhibition of HIF-1, not stimulation of GATA-2. Arch. Toxicol. 77, 267-273.

148. Li, C.L., Jiang, J., Fan, Y.Q., Fu, G.S., Wang, J.A., and Fan, W.M. (2009) Knockout of the tumor necrosis factor a receptor 1 gene can up-regulate erythropoietin receptor during myocardial ischemia-reperfusion injury in mice. Chin. Med. J. (Engl.) 122, 566-570.

149. Nagai, A., Nakagawa, E., Choi, H.B., Hatori, K., Kobayashi, S., and Kim, S.U. (2001) Erythropoietin and erythropoietin receptors in human CNS neurons, astrocytes, microglia, and oligodendrocytes grown in culture. $J$. Neuropathol. Exp. Neurol. 60, 386-392.

150. Pregi, N., Wenker, S., Vittori, D., Leiros, C.P., and Nesse, A. (2009) TNF-alpha-induced apoptosis is prevented by erythropoietin treatment on SH-SY5Y cells. Exp. Cell Res. 315, 419-431.

151. Clark, K.L., Halay, E.D., Lai, E., and Burley, S.K. (1993) Co-crystal structure of the HNF-3/fork head DNArecognition motif resembles histone H5. Nature 364, 412-420.

152. Larson, E.T., Eilers, B., Menon, S., Reiter, D., Ortmann, A., Young, M.J., and Lawrence, C.M. (2007) A wingedhelix protein from Sulfolobus turreted icosahedral virus points toward stabilizing disulfide bonds in the intracellular proteins of a hyperthermophilic virus. Virology 368, 249-261.

153. Jin, C., Marsden, I., Chen, X., and Liao, X. (1998) Sequence specific collective motions in a winged helix DNA binding domain detected by $15 \mathrm{~N}$ relaxation NMR. Biochemistry 37, 6179-6187.

154. Tsai, K.L., Sun, Y.J., Huang, C.Y., Yang, J.Y., Hung, M.C., and Hsiao, C.D. (2007) Crystal structure of the human FOXO3a-DBD/DNA complex suggests the effects of post-translational modification. Nucleic Acids Res. 35, 69846994.

155. Wijchers, P.J., Burbach, J.P., and Smidt, M.P. (2006) In control of biology: of mice, men and Foxes. Biochem. J. 397, 233-246.

156. Weigel, D., Jurgens, G., Kuttner, F., Seifert, E., and Jackle, H. (1989) The homeotic gene fork head encodes a nuclear protein and is expressed in the terminal regions of the Drosophila embryo. Cell 57, 645-658.

157. Kaestner, K.H., Knochel, W., and Martinez, D.E. (2000) Unified nomenclature for the winged helix/forkhead transcription factors. Genes Dev. 14, 142-146.

158. Maiese, K., Chong, Z.Z., and Shang, Y.C. (2007) "Sly as a FOXO": new paths with forkhead signaling in the brain. Curr. Neurovasc. Res. 4, 295-302.

159. Parry, P., Wei, Y., and Evans, G. (1994) Cloning and characterization of the $t(X ; 11)$ breakpoint from a leukemic cell line identify a new member of the forkhead gene family. Genes Chromosomes Cancer 11, 79-84.

160. Hillion, J., Le Coniat, M., Jonveaux, P., Berger, R., and Bernard, O.A. (1997) AF6q21, a novel partner of the MLL gene in $\mathrm{t}(6 ; 11)(\mathrm{q} 21 ; \mathrm{q} 23)$, defines a forkhead transcriptional factor subfamily. Blood $\mathbf{9 0}$, 3714-3719.

161. Castrillon, D.H., Miao, L., Kollipara, R., Horner, J.W., and DePinho, R.A. (2003) Suppression of ovarian follicle activation in mice by the transcription factor Foxo3a. Science 301, 215-218.

162. Furuyama, T., Nakazawa, T., Nakano, I., and Mori, N. (2000) Identification of the differential distribution patterns of mRNAs and consensus binding sequences for mouse DAF-16 homologues. Biochem. J. 349, 629-634.

163. Furuyama, T., Yamashita, H., Kitayama, K., Higami, Y., Shimokawa, I., and Mori, N. (2002) Effects of aging and caloric restriction on the gene expression of Foxo1, 3, and 4 (FKHR, FKHRL1, and AFX) in the rat skeletal muscles. Microsc. Res. Tech. 59, 331-334.

164. Hoekman, M.F., Jacobs, F.M., Smidt, M.P., and Burbach, J.P. (2006) Spatial and temporal expression of FoxO transcription factors in the developing and adult murine brain. Gene Expr. Patterns 6, 134-140.

165. Lappas, M., Lim, R., Riley, C., Rice, G.E., and Permezel, M. (2009) Localisation and expression of FoxO1 proteins in human gestational tissues. Placenta 30, 256-262.

166. Maiese, K., Chong, Z., Hou, J., and Shang, Y. (2009) The "O" class: crafting clinical care with FoxO transcription factors. In Forkhead Transcription Factors: Vital Elements in Biology and Medicine. Maiese, K., Ed. Landes Bioscience, Austin, TX.

167. Modur, V., Nagarajan, R., Evers, B.M., and Milbrandt, J. (2002) FOXO proteins regulate tumor necrosis factorrelated apoptosis inducing ligand expression. Implications for PTEN mutation in prostate cancer. J. Biol. Chem. 277, 47928-47937.

168. Biggs, W.H., 3rd, Cavenee, W.K., and Arden, K.C. (2001) Identification and characterization of members of the FKHR (FOX O) subclass of winged-helix transcription factors in the mouse. Mamm. Genome 12, 416-425.

169. Matsuzaki, H., Daitoku, H., Hatta, M., Tanaka, K., and Fukamizu, A. (2003) Insulin-induced phosphorylation of FKHR (Foxo1) targets to proteasomal degradation. Proc. Natl. Acad. Sci. U. S. A. 100, 11285-11290.

170. Plas, D.R. and Thompson, C.B. (2003) Akt activation promotes degradation of tuberin and FOXO3a via the proteasome. J. Biol. Chem. 278, 12361-12366.

171. Jagani, Z., Singh, A., and Khosravi-Far, R. (2008) FoxO tumor suppressors and BCR-ABL-induced leukemia: a matter of evasion of apoptosis. Biochim. Biophys. Acta 1785, 63-84.

172. Maiese, K., Chong, Z.Z., Shang, Y.C., and Hou, J. (2008) Clever cancer strategies with FoxO transcription factors. Cell Cycle 7, 3829-3839.

173. van der Horst, A. and Burgering, B.M. (2007) Stressing the role of FoxO proteins in lifespan and disease. Nat. Rev. Mol. Cell Biol. 8, 440-450. 
174. Taylor, D.M., Maxwell, M.M., Luthi-Carter, R., and Kazantsev, A.G. (2008) Biological and potential therapeutic roles of sirtuin deacetylases. Cell. Mol. Life Sci. 65, 4000-4018.

175. Zschoernig, B. and Mahlknecht, U. (2008) SIRTUIN 1: regulating the regulator. Biochem. Biophys. Res. Commun. 376, 251-255.

176. Matsuzaki, H., Daitoku, H., Hatta, M., Aoyama, H., Yoshimochi, K., and Fukamizu, A. (2005) Acetylation of Foxo1 alters its DNA-binding ability and sensitivity to phosphorylation. Proc. Natl. Acad. Sci. U. S. A. 102, 11278-11283.

177. Song, M., Park, J.E., Park, S.G., Lee do, H., Choi, H.K., Park, B.C., Ryu, S.E., Kim, J.H., and Cho, S. (2009) NSC87877, inhibitor of SHP-1/2 PTPs, inhibits dual-specificity phosphatase 26 (DUSP26). Biochem. Biophys. Res. Commun. 381, 491-495.

178. Chong, Z.Z., Li, F., and Maiese, K. (2005) Activating Akt and the brain's resources to drive cellular survival and prevent inflammatory injury. Histol. Histopathol. 20, 299-315.

179. Leong, M.L., Maiyar, A.C., Kim, B., O'Keeffe, B.A., and Firestone, G.L. (2003) Expression of the serum- and glucocorticoid-inducible protein kinase, $\mathrm{Sgk}$, is a cell survival response to multiple types of environmental stress stimuli in mammary epithelial cells. J. Biol. Chem. 278, 5871-5882.

180. Lehtinen, M.K., Yuan, Z., Boag, P.R., Yang, Y., Villen, J., Becker, E.B., DiBacco, S., de la Iglesia, N., Gygi, S., Blackwell, T.K., and Bonni, A. (2006) A conserved MST-FOXO signaling pathway mediates oxidative-stress responses and extends life span. Cell 125, 987-1001.

181. Song, J.J. and Lee, Y.J. (2008) Differential cleavage of Mst1 by caspase-7/-3 is responsible for TRAIL-induced activation of the MAPK superfamily. Cell. Signal. 20, 892-906.

182. Gayer, C.P., Chaturvedi, L.S., Wang, S., Craig, D.H., Flanigan, T., and Basson, M.D. (2009) Strain-induced proliferation requires the phosphatidylinositol 3-kinase/AKT/glycogen synthase kinase pathway. J. Biol. Chem. 284, 2001-2011.

183. An, J., Zhang, C., Polavarapu, R., Zhang, X., and Yepes, M. (2008) Tissue-type plasminogen activator and the lowdensity lipoprotein receptor-related protein induce Akt phosphorylation in the ischemic brain. Blood 112, 2787-2794.

184. Slaets, H., Dumont, D., Vanderlocht, J., Noben, J.P., Leprince, P., Robben, J., Hendriks, J., Stinissen, P., and Hellings, N. (2008) Leukemia inhibitory factor induces an antiapoptotic response in oligodendrocytes through Aktphosphorylation and up-regulation of 14-3-3. Proteomics 8, 1237-1247.

185. Williams, R., Dhillon, N.K., Hegde, S.T., Yao, H., Peng, F., Callen, S., Chebloune, Y., Davis, R.L., and Buch, S.J. (2009) Proinflammatory cytokines and HIV-1 synergistically enhance CXCL10 expression in human astrocytes. Glia 57, 734-743.

186. Rodriguez-Blanco, J., Martin, V., Herrera, F., Garcia-Santos, G., Antolin, I., and Rodriguez, C. (2008) Intracellular signaling pathways involved in post-mitotic dopaminergic PC12 cell death induced by 6-hydroxydopamine. J. Neurochem. 107, 127-140.

187. Anitha, M., Gondha, C., Sutliff, R., Parsadanian, A., Mwangi, S., Sitaraman, S.V., and Srinivasan, S. (2006) GDNF rescues hyperglycemia-induced diabetic enteric neuropathy through activation of the PI3K/Akt pathway. J. Clin. Invest. 116, 344-356.

188. Gaddini, L., Villa, M., Matteucci, A., Mallozzi, C., Petrucci, T.C., Di Stasi, A.M., Leo, L., Malchiodi-Albedi, F., and Pricci, F. (2009) Early effects of high glucose in retinal tissue cultures Renin-Angiotensin system-dependent and independent signaling. Neurobiol. Dis. 35, 278-285.

189. Burgos-Ramos, E., Martos-Moreno, G.A., Lopez, M.G., Herranz, R., Aguado-Llera, D., Egea, J., Frechilla, D., Cenarruzabeitia, E., Leon, R., Arilla-Ferreiro, E., Argente, J., and Barrios, V. (2009) The N-terminal tripeptide of insulin-like growth factor-I protects against beta-amyloid-induced somatostatin depletion by calcium and glycogen synthase kinase 3 beta modulation. J. Neurochem. 109, 360-370.

190. Burgos-Ramos, E., Puebla-Jimenez, L., and Arilla-Ferreiro, E. (2008) Minocycline provides protection against betaamyloid(25-35)-induced alterations of the somatostatin signaling pathway in the rat temporal cortex. Neuroscience 154, 1458-1466.

191. Burgos-Ramos, E., Puebla-Jimenez, L., and Arilla-Ferreiro, E. (2009) Minocycline prevents Abeta(25-35)-induced reduction of somatostatin and neprilysin content in rat temporal cortex. Life Sci. 84, 205-210.

192. Chong, Z.Z., Li, F., and Maiese, K. (2005) Erythropoietin requires NF-kappaB and its nuclear translocation to prevent early and late apoptotic neuronal injury during beta-amyloid toxicity. Curr. Neurovasc. Res. 2, 387-399.

193. Campos-Esparza, M.R., Sanchez-Gomez, M.V., and Matute, C. (2009) Molecular mechanisms of neuroprotection by two natural antioxidant polyphenols. Cell Calcium 45, 358-368.

194. Kim, K.H., Oudit, G.Y., and Backx, P.H. (2008) Erythropoietin protects against doxorubicin-induced cardiomyopathy via a phosphatidylinositol 3-kinase-dependent pathway. J. Pharmacol. Exp. Ther. 324, 160-169.

195. Tajes, M., Yeste-Velasco, M., Zhu, X., Chou, S.P., Smith, M.A., Pallas, M., Camins, A., and Casadesus, G. (2009) Activation of Akt by lithium: pro-survival pathways in aging. Mech. Ageing Dev. 130, 253-261.

196. van der Heide, L.P., Jacobs, F.M., Burbach, J.P., Hoekman, M.F., and Smidt, M.P. (2005) FoxO6 transcriptional activity is regulated by Thr26 and Ser184, independent of nucleo-cytoplasmic shuttling. Biochem. J. 391, 623-629.

197. Maiese, K., Chong, Z.Z., and Li, F. (2005) Driving cellular plasticity and survival through the signal transduction pathways of metabotropic glutamate receptors. Curr. Neurovasc. Res. 2, 425-446.

198. Salvesen, G.S. and Riedl, S.J. (2008) Caspase mechanisms. Adv. Exp. Med. Biol. 615, 13-23. 
199. Chong, Z.Z., Li, F., and Maiese, K. (2006) Group I metabotropic receptor neuroprotection requires Akt and its substrates that govern FOXO3a, Bim, and beta-catenin during oxidative stress. Curr. Neurovasc. Res. 3, $107-117$.

200. Chong, Z.Z., Lin, S.H., and Maiese, K. (2004) The NAD+ precursor nicotinamide governs neuronal survival during oxidative stress through protein kinase B coupled to FOXO3a and mitochondrial membrane potential. J. Cereb. Blood Flow Metab. 24, 728-743.

201. Obexer, P., Geiger, K., Ambros, P.F., Meister, B., and Ausserlechner, M.J. (2007) FKHRL1-mediated expression of Noxa and Bim induces apoptosis via the mitochondria in neuroblastoma cells. Cell Death Differ. 14, 534-547.

202. Gomez-Gutierrez, J.G., Souza, V., Hao, H.Y., Montes de Oca-Luna, R., Dong, Y.B., Zhou, H.S., and McMasters, K.M. (2006) Adenovirus-mediated gene transfer of FKHRL1 triple mutant efficiently induces apoptosis in melanoma cells. Cancer Biol. Ther. 5, 875-883.

203. Maiese, K., Chong, Z.Z., and Shang, Y.C. (2007) Mechanistic insights into diabetes mellitus and oxidative stress. Curr. Med. Chem. 14, 1729-1738.

204. Maiese, K., Morhan, S.D., and Chong, Z.Z. (2007) Oxidative stress biology and cell injury during type 1 and type 2 diabetes mellitus. Curr. Neurovasc. Res. 4, 63-71.

205. Maiese, K. (2008) Diabetic stress: new triumphs and challenges to maintain vascular longevity. Expert Rev. Cardiovasc. Ther. 6, 281-284.

206. Hao, J., Shen, W., Tian, C., Liu, Z., Ren, J., Luo, C., Long, J., Sharman, E., and Liu, J. (2009) Mitochondrial nutrients improve immune dysfunction in the type 2 diabetic Goto-Kakizaki rats. J. Cell. Mol. Med. 13, 701-711.

207. Kuhad, A., Bishnoi, M., Tiwari, V., and Chopra, K. (2009) Suppression of NF-kappabeta signaling pathway by tocotrienol can prevent diabetes associated cognitive deficits. Pharmacol. Biochem. Behav. 92, 251-259.

208. Wu, S.Y., Wang, G.F., Liu, Z.Q., Rao, J.J., Lu, L., Xu, W., Wu, S.G., and Zhang, J.J. (2009) Effect of geniposide, a hypoglycemic glucoside, on hepatic regulating enzymes in diabetic mice induced by a high-fat diet and streptozotocin. Acta Pharmacol. Sin. 30, 202-208.

209. Guarnieri, G., Zanetti, M., Vinci, P., Cattin, M.R., and Barazzoni, R. (2009) Insulin resistance in chronic uremia. J. Ren. Nutr. 19, 20-24.

210. Gossai, D. and Lau-Cam, C.A. (2009) The effects of taurine, taurine homologs and hypotaurine on cell and membrane antioxidative system alterations caused by type 2 diabetes in rat erythrocytes. Adv. Exp. Med. Biol. 643, 359-368.

211. Donahoe, S.M., Stewart, G.C., McCabe, C.H., Mohanavelu, S., Murphy, S.A., Cannon, C.P., and Antman, E.M. (2007) Diabetes and mortality following acute coronary syndromes. JAMA 298, 765-775.

212. Mojiminiyi, O.A., Abdella, N.A., Zaki, M.Y., El Gebely, S.A., Mohamedi, H.M., and Aldhahi, W.A. (2006) Prevalence and associations of low plasma erythropoietin in patients with Type 2 diabetes mellitus. Diabet. Med. 23, 839-844.

213. Symeonidis, A., Kouraklis-Symeonidis, A., Psiroyiannis, A., Leotsinidis, M., Kyriazopoulou, V., Vassilakos, P., Vagenakis, A., and Zoumbos, N. (2006) Inappropriately low erythropoietin response for the degree of anemia in patients with noninsulin-dependent diabetes mellitus. Ann. Hematol. 85, 79-85.

214. Thomas, M.C., Cooper, M.E., Tsalamandris, C., MacIsaac, R., and Jerums, G. (2005) Anemia with impaired erythropoietin response in diabetic patients. Arch. Intern. Med. 165, 466-469.

215. Teramo, K., Kari, M.A., Eronen, M., Markkanen, H., and Hiilesmaa, V. (2004) High amniotic fluid erythropoietin levels are associated with an increased frequency of fetal and neonatal morbidity in type 1 diabetic pregnancies. Diabetologia 47, 1695-1703.

216. Duarte, A.I., Proenca, T., Oliveira, C.R., Santos, M.S., and Rego, A.C. (2006) Insulin restores metabolic function in cultured cortical neurons subjected to oxidative stress. Diabetes 55, 2863-2870.

217. Silverberg, D.S., Wexler, D., Iaina, A., and Schwartz, D. (2006) The interaction between heart failure and other heart diseases, renal failure, and anemia. Semin. Nephrol. 26, 296-306.

218. Chong, Z.Z., Shang, Y.C., and Maiese, K. (2007) Vascular injury during elevated glucose can be mitigated by erythropoietin and Wnt signaling. Curr. Neurovasc. Res. 4, 194-204.

219. Mason-Garcia, M., Beckman, B.S., Brookins, J.W., Powell, J.S., Lanham, W., Blaisdell, S., Keay, L., Li, S.C., and Fisher, J.W. (1990) Development of a new radioimmunoassay for erythropoietin using recombinant erythropoietin. Kidney Int. 38, 969-975.

220. Namiuchi, S., Kagaya, Y., Ohta, J., Shiba, N., Sugi, M., Oikawa, M., Kunii, H., Yamao, H., Komatsu, N., Yui, M., Tada, H., Sakuma, M., Watanabe, J., Ichihara, T., and Shirato, K. (2005) High serum erythropoietin level is associated with smaller infarct size in patients with acute myocardial infarction who undergo successful primary percutaneous coronary intervention. J. Am. Coll. Cardiol. 45, 1406-1412.

221. Chattopadhyay, M., Walter, C., Mata, M., and Fink, D.J. (2009) Neuroprotective effect of herpes simplex virusmediated gene transfer of erythropoietin in hyperglycemic dorsal root ganglion neurons. Brain 132, 879-888.

222. Avasarala, J.R. and Konduru, S.S. (2005) Recombinant erythropoietin down-regulates IL-6 and CXCR4 genes in TNF-alpha-treated primary cultures of human microvascular endothelial cells: implications for multiple sclerosis. $J$. Mol. Neurosci. 25, 183-189.

223. Miki, T., Miura, T., Yano, T., Takahashi, A., Sakamoto, J., Tanno, M., Kobayashi, H., Ikeda, Y., Nishihara, M., Naitoh, K., Ohori, K., and Shimamoto, K. (2006) Alteration in erythropoietin-induced cardioprotective signaling by postinfarct ventricular remodeling. J. Pharmacol. Exp. Ther. 317, 68-75. 
224. Espada, J., Calvo, M.B., Diaz-Prado, S., and Medina, V. (2009) Wnt signalling and cancer stem cells. Clin. Transl. Oncol. 11, 411-427.

225. Wilusz, M. and Majka, M. (2008) Role of the Wnt/beta-catenin network in regulating hematopoiesis. Arch. Immunol. Ther. Exp. (Warsz.) 56, 257-266.

226. Maiese, K., Li, F., Chong, Z.Z., and Shang, Y.C. (2008) The Wnt signaling pathway: aging gracefully as a protectionist? Pharmacol. Ther. 118, 58-81.

227. Kikuchi, A., Yamamoto, H., and Sato, A. (2009) Selective activation mechanisms of Wnt signaling pathways. Trends Cell Biol. 19, 119-129.

228. Grant, S.F., Thorleifsson, G., Reynisdottir, I., Benediktsson, R., Manolescu, A., Sainz, J., Helgason, A., Stefansson, H., Emilsson, V., Helgadottir, A., Styrkarsdottir, U., Magnusson, K.P., Walters, G.B., Palsdottir, E., Jonsdottir, T., Gudmundsdottir, T., Gylfason, A., Saemundsdottir, J., Wilensky, R.L., Reilly, M.P., Rader, D.J., Bagger, Y., Christiansen, C., Gudnason, V., Sigurdsson, G., Thorsteinsdottir, U., Gulcher, J.R., Kong, A., and Stefansson, K. (2006) Variant of transcription factor 7-like 2 (TCF7L2) gene confers risk of type 2 diabetes. Nat. Genet. 38, 320323.

229. Lehman, D.M., Hunt, K.J., Leach, R.J., Hamlington, J., Arya, R., Abboud, H.E., Duggirala, R., Blangero, J., Goring, H.H., and Stern, M.P. (2007) Haplotypes of transcription factor 7-like 2 (TCF7L2) gene and its upstream region are associated with type 2 diabetes and age of onset in Mexican Americans. Diabetes 56, 389-393.

230. Scott, L.J., Bonnycastle, L.L., Willer, C.J., Sprau, A.G., Jackson, A.U., Narisu, N., Duren, W.L., Chines, P.S., Stringham, H.M., Erdos, M.R., Valle, T.T., Tuomilehto, J., Bergman, R.N., Mohlke, K.L., Collins, F.S., and Boehnke, M. (2006) Association of transcription factor 7-like 2 (TCF7L2) variants with type 2 diabetes in a Finnish sample. Diabetes 55, 2649-2653.

231. Guo, Y.F., Xiong, D.H., Shen, H., Zhao, L.J., Xiao, P., Guo, Y., Wang, W., Yang, T.L., Recker, R.R., and Deng, H.W. (2006) Polymorphisms of the low-density lipoprotein receptor-related protein 5 (LRP5) gene are associated with obesity phenotypes in a large family-based association study. J. Med. Genet. 43, 798-803.

232. Wright, W.S., Longo, K.A., Dolinsky, V.W., Gerin, I., Kang, S., Bennett, C.N., Chiang, S.H., Prestwich, T.C., Gress, C., Burant, C.F., Susulic, V.S., and Macdougald, O.A. (2007) Wnt10b inhibits obesity in ob/ob and agouti mice. Diabetes 56, 295-303.

233. Lin, C.L., Wang, J.Y., Huang, Y.T., Kuo, Y.H., Surendran, K., and Wang, F.S. (2006) Wnt/beta-catenin signaling modulates survival of high glucose-stressed mesangial cells. J. Am. Soc. Nephrol. 17, 2812-2820.

234. Lin, K., Dorman, J.B., Rodan, A., and Kenyon, C. (1997) daf-16: an HNF-3/forkhead family member that can function to double the life-span of Caenorhabditis elegans. Science 278, 1319-1322.

235. Ogg, S., Paradis, S., Gottlieb, S., Patterson, G.I., Lee, L., Tissenbaum, H.A., and Ruvkun, G. (1997) The Fork head transcription factor DAF-16 transduces insulin-like metabolic and longevity signals in C. elegans. Nature 389, 994999.

236. Guo, S., Rena, G., Cichy, S., He, X., Cohen, P., and Unterman, T. (1999) Phosphorylation of serine 256 by protein kinase B disrupts transactivation by FKHR and mediates effects of insulin on insulin-like growth factor-binding protein-1 promoter activity through a conserved insulin response sequence. J. Biol. Chem. 274, 17184-17192.

237. Nakae, J., Park, B.C., and Accili, D. (1999) Insulin stimulates phosphorylation of the forkhead transcription factor FKHR on serine 253 through a Wortmannin-sensitive pathway. J. Biol. Chem. 274, 15982-15985.

238. Kim, J.R., Jung, H.S., Bae, S.W., Kim, J.H., Park, B.L., Choi, Y.H., Cho, H.Y., Cheong, H.S., and Shin, H.D. (2006) Polymorphisms in FOXO gene family and association analysis with BMI. Obesity (Silver Spring) 14, $188-193$.

239. Marchetti, V., Menghini, R., Rizza, S., Vivanti, A., Feccia, T., Lauro, D., Fukamizu, A., Lauro, R., and Federici, M. (2006) Benfotiamine counteracts glucose toxicity effects on endothelial progenitor cell differentiation via Akt/FoxO signaling. Diabetes 55, 2231-2237.

240. Fallarino, F., Bianchi, R., Orabona, C., Vacca, C., Belladonna, M.L., Fioretti, M.C., Serreze, D.V., Grohmann, U., and Puccetti, P. (2004) CTLA-4-Ig activates forkhead transcription factors and protects dendritic cells from oxidative stress in nonobese diabetic mice. J. Exp. Med. 200, 1051-1062.

241. Nakae, J., Cao, Y., Oki, M., Orba, Y., Sawa, H., Kiyonari, H., Iskandar, K., Suga, K., Lombes, M., and Hayashi, Y. (2008) Forkhead transcription factor FoxO1 in adipose tissue regulates energy storage and expenditure. Diabetes 57, 563-576.

242. Puig, O. and Tjian, R. (2005) Transcriptional feedback control of insulin receptor by dFOXO/FOXO1. Genes Dev. 19, 2435-2446.

243. Kamagate, A. and Dong, H.H. (2008) Foxo1 integrates insulin signaling to VLDL production. Cell Cycle 7, 31623170 .

244. Ni, Y.G., Wang, N., Cao, D.J., Sachan, N., Morris, D.J., Gerard, R.D., Kuro, O.M., Rothermel, B.A., and Hill, J.A. (2007) FoxO transcription factors activate Akt and attenuate insulin signaling in heart by inhibiting protein phosphatases. Proc. Natl. Acad. Sci. U. S. A. 104, 20517-20522.

245. Kamei, Y., Miura, S., Suzuki, M., Kai, Y., Mizukami, J., Taniguchi, T., Mochida, K., Hata, T., Matsuda, J., Aburatani, H., Nishino, I., and Ezaki, O. (2004) Skeletal muscle FOXO1 (FKHR) transgenic mice have less skeletal muscle mass, down-regulated Type I (slow twitch/red muscle) fiber genes, and impaired glycemic control. J. Biol. Chem. 279, 41114-41123. 
246. Liu, C.M., Yang, Z., Liu, C.W., Wang, R., Tien, P., Dale, R., and Sun, L.Q. (2007) Effect of RNA oligonucleotide targeting Foxo-1 on muscle growth in normal and cancer cachexia mice. Cancer Gene Ther. 14, 945-952.

247. Sandri, M., Lin, J., Handschin, C., Yang, W., Arany, Z.P., Lecker, S.H., Goldberg, A.L., and Spiegelman, B.M. (2006) PGC-1alpha protects skeletal muscle from atrophy by suppressing FoxO3 action and atrophy-specific gene transcription. Proc. Natl. Acad. Sci. U. S. A. 103, 16260-16265.

248. Maiese, K., Chong, Z.Z., Hou, J., and Shang, Y. (2009) The vitamin nicotinamide: translating nutrition into clinical care. Molecules 14, 3446-3485.

249. Balan, V., Miller, G.S., Kaplun, L., Balan, K., Chong, Z.Z., Li, F., Kaplun, A., VanBerkum, M.F., Arking, R., Freeman, D.C., Maiese, K., and Tzivion, G. (2008) Life span extension and neuronal cell protection by Drosophila nicotinamidase. J. Biol. Chem. 283, 27810-27819.

250. Chong, Z.Z. and Maiese, K. (2008) Enhanced tolerance against early and late apoptotic oxidative stress in mammalian neurons through nicotinamidase and sirtuin mediated pathways. Curr. Neurovasc. Res. 5, 159-170.

251. Solar, P., Koval, J., Mikes, J., Kleban, J., Solarova, Z., Lazur, J., Hodorova, I., Fedorocko, P., and Sytkowski, A.J. (2008) Erythropoietin inhibits apoptosis induced by photodynamic therapy in ovarian cancer cells. Mol. Cancer Ther. 7, 2263-2271.

252. Sauvageot, C.M., Kesari, S., and Stiles, C.D. (2007) Molecular pathogenesis of adult brain tumors and the role of stem cells. Neurol. Clin. 25, 891-924, vii.

253. Anagnostou, A., Lee, E.S., Kessimian, N., Levinson, R., and Steiner, M. (1990) Erythropoietin has a mitogenic and positive chemotactic effect on endothelial cells. Proc. Natl. Acad. Sci. U. S. A. 87, 5978-5982.

254. Ashley, R.A., Dubuque, S.H., Dvorak, B., Woodward, S.S., Williams, S.K., and Kling, P.J. (2002) Erythropoietin stimulates vasculogenesis in neonatal rat mesenteric microvascular endothelial cells. Pediatr. Res. 51, 472-478.

255. Li, Y., Lu, Z., Keogh, C.L., Yu, S.P., and Wei, L. (2007) Erythropoietin-induced neurovascular protection, angiogenesis, and cerebral blood flow restoration after focal ischemia in mice. J. Cereb. Blood Flow Metab. 27, 1043-1054.

256. Reinders, M.E., Rabelink, T.J., and Briscoe, D.M. (2006) Angiogenesis and endothelial cell repair in renal disease and allograft rejection. J. Am. Soc. Nephrol. 17, 932-942.

257. Zhang, D., Zhang, F., Zhang, Y., Gao, X., Li, C., Ma, W., and Cao, K. (2007) Erythropoietin enhances the angiogenic potency of autologous bone marrow stromal cells in a rat model of myocardial infarction. Cardiology 108, 228-236.

258. Zhang, S.X. and Ma, J.X. (2007) Ocular neovascularization: implication of endogenous angiogenic inhibitors and potential therapy. Prog. Retin. Eye Res. 26, 1-37.

259. Heeschen, C., Aicher, A., Lehmann, R., Fichtlscherer, S., Vasa, M., Urbich, C., Mildner-Rihm, C., Martin, H., Zeiher, A.M., and Dimmeler, S. (2003) Erythropoietin is a potent physiologic stimulus for endothelial progenitor cell mobilization. Blood 102, 1340-1346.

260. Koh, S.H., Noh, M.Y., Cho, G.W., Kim, K.S., and Kim, S.H. (2009) Erythropoietin increases the motility of human bone marrow-multipotent stromal cells (hBM-MSCs) and enhances the production of neurotrophic factors from hBMMSCs. Stem Cells Dev. 18, 411-421.

261. Brunner, S., Winogradow, J., Huber, B.C., Zaruba, M.M., Fischer, R., David, R., Assmann, G., Herbach, N., Wanke, R., Mueller-Hoecker, J., and Franz, W.M. (2009) Erythropoietin administration after myocardial infarction in mice attenuates ischemic cardiomyopathy associated with enhanced homing of bone marrow-derived progenitor cells via the CXCR-4/SDF-1 axis. FASEB J. 23, 351-361.

262. Lin, J.S., Chen, Y.S., Chiang, H.S., and Ma, M.C. (2008) Hypoxic preconditioning protects rat hearts against ischaemia-reperfusion injury: role of erythropoietin on progenitor cell mobilization. J. Physiol. 586, 5757-5769.

263. Uitterdijk, A., Groenendijk, B.C., and van Der Giessen, W.J. (2009) Stem cell therapy for chronic heart failure. Hellenic J. Cardiol. 50, 127-132.

264. Bakker, W.J., van Dijk, T.B., Parren-van Amelsvoort, M., Kolbus, A., Yamamoto, K., Steinlein, P., Verhaak, R.G., Mak, T.W., Beug, H., Lowenberg, B., and von Lindern, M. (2007) Differential regulation of Foxo3a target genes in erythropoiesis. Mol. Cell. Biol. 27, 3839-3854.

265. Cariou, A., Claessens, Y.E., Pene, F., Marx, J.S., Spaulding, C., Hababou, C., Casadevall, N., Mira, J.P., Carli, P., and Hermine, O. (2008) Early high-dose erythropoietin therapy and hypothermia after out-of-hospital cardiac arrest: a matched control study. Resuscitation 76, 397-404.

266. Miyamoto, K., Araki, K.Y., Naka, K., Arai, F., Takubo, K., Yamazaki, S., Matsuoka, S., Miyamoto, T., Ito, K., Ohmura, M., Chen, C., Hosokawa, K., Nakauchi, H., Nakayama, K., Nakayama, K.I., Harada, M., Motoyama, N., Suda, T., and Hirao, A. (2007) Foxo3a is essential for maintenance of the hematopoietic stem cell pool. Cell Stem Cell 1, 101-112.

267. Tothova, Z., Kollipara, R., Huntly, B.J., Lee, B.H., Castrillon, D.H., Cullen, D.E., McDowell, E.P., Lazo-Kallanian, S., Williams, I.R., Sears, C., Armstrong, S.A., Passegue, E., DePinho, R.A., and Gilliland, D.G. (2007) FoxOs are critical mediators of hematopoietic stem cell resistance to physiologic oxidative stress. Cell 128, 325-339.

268. Furukawa-Hibi, Y., Yoshida-Araki, K., Ohta, T., Ikeda, K., and Motoyama, N. (2002) FOXO forkhead transcription factors induce G(2)-M checkpoint in response to oxidative stress. J. Biol. Chem. 277, 26729-26732.

269. Liu, L., Rajareddy, S., Reddy, P., Du, C., Jagarlamudi, K., Shen, Y., Gunnarsson, D., Selstam, G., Boman, K., and Liu, K. (2007) Infertility caused by retardation of follicular development in mice with oocyte-specific expression of Foxo3a. Development 134, 199-209. 
270. Watkins, W.J., Umbers, A.J., Woad, K.J., Harris, S.E., Winship, I.M., Gersak, K., and Shelling, A.N. (2006) Mutational screening of FOXO3A and FOXO1A in women with premature ovarian failure. Fertil. Steril. 86, 15181521.

271. Wu, Y., Peng, H., Cui, M., Whitney, N.P., Huang, Y., and Zheng, J.C. (2009) CXCL12 increases human neural progenitor cell proliferation through Akt-1/FOXO3a signaling pathway. J. Neurochem. 109, 1157-1167.

272. Hosaka, T., Biggs, W.H., 3rd, Tieu, D., Boyer, A.D., Varki, N.M., Cavenee, W.K., and Arden, K.C. (2004) Disruption of forkhead transcription factor (FOXO) family members in mice reveals their functional diversification. Proc. Natl. Acad. Sci. U. S. A. 101, 2975-2980.

273. Furuyama, T., Kitayama, K., Shimoda, Y., Ogawa, M., Sone, K., Yoshida-Araki, K., Hisatsune, H., Nishikawa, S., Nakayama, K., Nakayama, K., Ikeda, K., Motoyama, N., and Mori, N. (2004) Abnormal angiogenesis in Foxo1 (Fkhr)-deficient mice. J. Biol. Chem. 279, 34741-34749.

274. Evans-Anderson, H.J., Alfieri, C.M., and Yutzey, K.E. (2008) Regulation of cardiomyocyte proliferation and myocardial growth during development by FOXO transcription factors. Circ. Res. 102, 686-694.

275. Li, H.H., Willis, M.S., Lockyer, P., Miller, N., McDonough, H., Glass, D.J., and Patterson, C. (2007) Atrogin-1 inhibits Akt-dependent cardiac hypertrophy in mice via ubiquitin-dependent coactivation of forkhead proteins. J. Clin. Invest. 117, 3211-3223.

276. Abid, M.R., Yano, K., Guo, S., Patel, V.I., Shrikhande, G., Spokes, K.C., Ferran, C., and Aird, W.C. (2005) Forkhead transcription factors inhibit vascular smooth muscle cell proliferation and neointimal hyperplasia. J. Biol. Chem. 280, 29864-29873.

277. Liu, Z.P., Wang, Z., Yanagisawa, H., and Olson, E.N. (2005) Phenotypic modulation of smooth muscle cells through interaction of Foxo4 and myocardin. Dev. Cell 9, 261-270.

278. Li, H., Liang, J., Castrillon, D.H., DePinho, R.A., Olson, E.N., and Liu, Z.P. (2007) FoxO4 regulates tumor necrosis factor alpha-directed smooth muscle cell migration by activating matrix metalloproteinase 9 gene transcription. Mol. Cell. Biol. 27, 2676-2686.

279. Goettsch, W., Gryczka, C., Korff, T., Ernst, E., Goettsch, C., Seebach, J., Schnittler, H.J., Augustin, H.G., and Morawietz, H. (2008) Flow-dependent regulation of angiopoietin-2. J. Cell. Physiol. 214, 491-503.

280. Morris, J.B., Kenney, B., Huynh, H., and Woodcock, E.A. (2005) Regulation of the proapoptotic factor FOXO1 (FKHR) in cardiomyocytes by growth factors and alpha1-adrenergic agonists. Endocrinology 146, 4370-4376.

281. Sedding, D.G., Seay, U., Fink, L., Heil, M., Kummer, W., Tillmanns, H., and Braun-Dullaeus, R.C. (2003) Mechanosensitive p27Kip1 regulation and cell cycle entry in vascular smooth muscle cells. Circulation 108, 616622.

282. Hannenhalli, S., Putt, M.E., Gilmore, J.M., Wang, J., Parmacek, M.S., Epstein, J.A., Morrisey, E.E., Margulies, K.B., and Cappola, T.P. (2006) Transcriptional genomics associates FOX transcription factors with human heart failure. Circulation 114, 1269-1276.

283. Liu, R., Suzuki, A., Guo, Z., Mizuno, Y., and Urabe, T. (2006) Intrinsic and extrinsic erythropoietin enhances neuroprotection against ischemia and reperfusion injury in vitro. J. Neurochem. 96, 1101-1110.

284. Meloni, B.P., Tilbrook, P.A., Boulos, S., Arthur, P.G., and Knuckey, N.W. (2006) Erythropoietin preconditioning in neuronal cultures: signaling, protection from in vitro ischemia, and proteomic analysis. J. Neurosci. Res. 83, 584-593.

285. Wei, L., Han, B.H., Li, Y., Keogh, C.L., Holtzman, D.M., and Yu, S.P. (2006) Cell death mechanism and protective effect of erythropoietin after focal ischemia in the whisker-barrel cortex of neonatal rats. J. Pharmacol. Exp. Ther. 317, 109-116.

286. Yu, Y.P., Xu, Q.Q., Zhang, Q., Zhang, W.P., Zhang, L.H., and Wei, E.Q. (2005) Intranasal recombinant human erythropoietin protects rats against focal cerebral ischemia. Neurosci. Lett. 387, 5-10.

287. Montero, M., Poulsen, F.R., Noraberg, J., Kirkeby, A., van Beek, J., Leist, M., and Zimmer, J. (2007) Comparison of neuroprotective effects of erythropoietin (EPO) and carbamylerythropoietin (CEPO) against ischemia-like oxygenglucose deprivation (OGD) and NMDA excitotoxicity in mouse hippocampal slice cultures. Exp. Neurol. 204, 106117.

288. Yamasaki, M., Mishima, H.K., Yamashita, H., Kashiwagi, K., Murata, K., Minamoto, A., and Inaba, T. (2005) Neuroprotective effects of erythropoietin on glutamate and nitric oxide toxicity in primary cultured retinal ganglion cells. Brain Res. 1050, 15-26.

289. Yoo, J.Y., Won, Y.J., Lee, J.H., Kim, J.U., Sung, I.Y., Hwang, S.J., Kim, M.J., and Hong, H.N. (2009) Neuroprotective effects of erythropoietin posttreatment against kainate-induced excitotoxicity in mixed spinal cultures. J. Neurosci. Res. 87, 150-163.

290. Bienvenu, A.L., Ferrandiz, J., Kaiser, K., Latour, C., and Picot, S. (2008) Artesunate-erythropoietin combination for murine cerebral malaria treatment. Acta Trop. 106, 104-108.

291. Casals-Pascual, C., Idro, R., Picot, S., Roberts, D.J., and Newton, C.R. (2009) Can erythropoietin be used to prevent brain damage in cerebral malaria? Trends Parasitol. 25, 30-36.

292. Kaiser, K., Texier, A., Ferrandiz, J., Buguet, A., Meiller, A., Latour, C., Peyron, F., Cespuglio, R., and Picot, S. (2006) Recombinant human erythropoietin prevents the death of mice during cerebral malaria. J. Infect. Dis. 193, 987-995.

293. Aoshiba, K., Onizawa, S., Tsuji, T., and Nagai, A. (2009) Therapeutic effects of erythropoietin in murine models of endotoxin shock. Crit. Care Med. 37, 889-898. 
294. Wagner, F., Baumgart, K., Simkova, V., Georgieff, M., Radermacher, P., and Calzia, E. (2008) Year in review 2007: Critical Care--shock. Crit. Care 12, 227.

295. Chen, H.H., Tarng, D.C., Lee, K.F., Wu, C.Y., and Chen, Y.C. (2008) Epoetin alfa and darbepoetin alfa: effects on ventricular hypertrophy in patients with chronic kidney disease. J. Nephrol. 21, 543-549.

296. Mao, W., Iwai, C., Liu, J., Sheu, S.S., Fu, M., and Liang, C.S. (2008) Darbepoetin alfa exerts a cardioprotective effect in autoimmune cardiomyopathy via reduction of ER stress and activation of the PI3K/Akt and STAT3 pathways. $J$. Mol. Cell. Cardiol. 45, 250-260.

297. Ma, R., Xiong, N., Huang, C., Tang, Q., Hu, B., Xiang, J., and Li, G. (2009) Erythropoietin protects PC12 cells from beta-amyloid(25-35)-induced apoptosis via PI3K/Akt signaling pathway. Neuropharmacology 56, 1027-1034.

298. Sun, Z.K., Yang, H.Q., Pan, J., Zhen, H., Wang, Z.Q., Chen, S.D., and Ding, J.Q. (2008) Protective effects of erythropoietin on tau phosphorylation induced by beta-amyloid. J. Neurosci. Res. 86, 3018-3027.

299. Ucan, B.H., Irkorucu, O., Cakmak, G.K., Tascilar, O., Tekin, I.O., Acikgoz, S., Emre, A.U., Bahadir, B., Ankarali, H., and Comert, M. (2009) Erythropoietin: a possible cytoprotective cytokine in acute necrotizing pancreatitis. $J$. Hepatobiliary Pancreat. Surg. 16, 530-537.

300. Tascilar, O., Cakmak, G.K., Tekin, I.O., Emre, A.U., Ucan, B.H., Bahadir, B., Acikgoz, S., Irkorucu, O., Karakaya, K., Balbaloglu, H., Kertis, G., Ankarali, H., and Comert, M. (2007) Protective effects of erythropoietin against acute lung injury in a rat model of acute necrotizing pancreatitis. World J. Gastroenterol. 13, 6172-6182.

301. Wu, H., Dong, G., Liu, H., Xu, B., Li, D., and Jing, H. (2009) Erythropoietin attenuates ischemia-reperfusion induced lung injury by inhibiting tumor necrosis factor-alpha and matrix metalloproteinase-9 expression. Eur. J. Pharmacol. 602, 406-412.

302. Chen, J., Connor, K.M., Aderman, C.M., Willett, K.L., Aspegren, O.P., and Smith, L.E. (2009) Suppression of retinal neovascularization by erythropoietin siRNA in a mouse model of proliferative retinopathy. Invest. Ophthalmol. Vis. Sci. 50, 1329-1335.

303. Wang, Z.Y., Shen, L.J., Tu, L., Hu, D.N., Liu, G.Y., Zhou, Z.L., Lin, Y., Chen, L.H., and Qu, J. (2009) Erythropoietin protects retinal pigment epithelial cells from oxidative damage. Free Radic. Biol. Med. 46, 1032-1041.

304. Zhong, Y., Yao, H., Deng, L., Cheng, Y., and Zhou, X. (2007) Promotion of neurite outgrowth and protective effect of erythropoietin on the retinal neurons of rats. Graefes Arch. Clin. Exp. Ophthalmol. 245, 1859-1867.

305. Zhong, Y.S., Liu, X.H., Cheng, Y., and Min, Y.J. (2008) Erythropoietin with retrobulbar administration protects retinal ganglion cells from acute elevated intraocular pressure in rats. J. Ocul. Pharmacol. Ther. 24, 453-459.

306. Tsai, J.C., Song, B.J., Wu, L., and Forbes, M. (2007) Erythropoietin: a candidate neuroprotective agent in the treatment of glaucoma. J. Glaucoma 16, 567-571.

307. King, V.R., Averill, S.A., Hewazy, D., Priestley, J.V., Torup, L., and Michael-Titus, A.T. (2007) Erythropoietin and carbamylated erythropoietin are neuroprotective following spinal cord hemisection in the rat. Eur. J. Neurosci. 26, 90-100.

308. Okutan, O., Solaroglu, I., Beskonakli, E., and Taskin, Y. (2007) Recombinant human erythropoietin decreases myeloperoxidase and caspase-3 activity and improves early functional results after spinal cord injury in rats. J. Clin. Neurosci. 14, 364-368.

309. Verdonck, O., Lahrech, H., Francony, G., Carle, O., Farion, R., Van de Looij, Y., Remy, C., Segebarth, C., and Payen, J.F. (2007) Erythropoietin protects from post-traumatic edema in the rat brain. J. Cereb. Blood Flow Metab. 27, 1369-1376.

310. Cherian, L., Goodman, J.C., and Robertson, C. (2007) Neuroprotection with erythropoietin administration following controlled cortical impact injury in rats. J. Pharmacol. Exp. Ther. 322, 789-794.

311. Chu, K., Jung, K.H., Lee, S.T., Kim, J.H., Kang, K.M., Kim, H.K., Lim, J.S., Park, H.K., Kim, M., Lee, S.K., and Roh, J.K. (2008) Erythropoietin reduces epileptogenic processes following status epilepticus. Epilepsia 49, 17231732 .

312. Nadam, J., Navarro, F., Sanchez, P., Moulin, C., Georges, B., Laglaine, A., Pequignot, J.M., Morales, A., Ryvlin, P., and Bezin, L. (2007) Neuroprotective effects of erythropoietin in the rat hippocampus after pilocarpine-induced status epilepticus. Neurobiol. Dis. 25, 412-426.

313. Nakamura, T. and Sakamoto, K. (2007) Forkhead transcription factor FOXO subfamily is essential for reactive oxygen species-induced apoptosis. Mol. Cell. Endocrinol. 281(1-2), 47-55.

314. Barthelemy, C., Henderson, C.E., and Pettmann, B. (2004) Foxo3a induces motoneuron death through the Fas pathway in cooperation with JNK. BMC Neurosci. 5, 48.

315. You, H., Yamamoto, K., and Mak, T.W. (2006) Regulation of transactivation-independent proapoptotic activity of p53 by FOXO3a. Proc. Natl. Acad. Sci. U. S. A. 103, 9051-9056.

316. Won, C.K., Ji, H.H., and Koh, P.O. (2006) Estradiol prevents the focal cerebral ischemic injury-induced decrease of forkhead transcription factors phosphorylation. Neurosci. Lett. 398, 39-43.

317. Caporali, A., Sala-Newby, G.B., Meloni, M., Graiani, G., Pani, E., Cristofaro, B., Newby, A.C., Madeddu, P., and Emanueli, C. (2008) Identification of the prosurvival activity of nerve growth factor on cardiac myocytes. Cell Death Differ. 15, 299-311.

318. Erol, A. (2009) Unraveling the molecular mechanisms behind the metabolic basis of sporadic Alzheimer's disease. $J$. Alzheimers Dis. [Epub ahead of print] 
319. Lu, J., Wu, D.M., Zheng, Y.L., Sun, D.X., Hu, B., Shan, Q., Zhang, Z.F., and Fan, S.H. (2009) Trace amounts of copper exacerbate beta amyloid-induced neurotoxicity in the cholesterol-fed mice through TNF-mediated inflammatory pathway. Brain Behav. Immun. 23, 193-203.

320. Majd, S., Rastegar, K., Zarifkar, A., and Takhshid, M.A. (2007) Fibrillar beta-amyloid (Abeta) (1-42) elevates extracellular Abeta in cultured hippocampal neurons of adult rats. Brain Res. 1185, 321-327.

321. Majd, S., Zarifkar, A., Rastegar, K., and Takhshid, M.A. (2008) Different fibrillar Abeta 1-42 concentrations induce adult hippocampal neurons to reenter various phases of the cell cycle. Brain Res. 1218, 224-229.

322. Smith, W.W., Norton, D.D., Gorospe, M., Jiang, H., Nemoto, S., Holbrook, N.J., Finkel, T., and Kusiak, J.W. (2005) Phosphorylation of p66Shc and forkhead proteins mediates Abeta toxicity. J. Cell Biol. 169, 331-339.

323. Mercado-Gomez, O., Hernandez-Fonseca, K., Villavicencio-Queijeiro, A., Massieu, L., Chimal-Monroy, J., and Arias, C. (2008) Inhibition of Wnt and PI3K signaling modulates GSK-3beta activity and induces morphological changes in cortical neurons: role of tau phosphorylation. Neurochem. Res. 33, 1599-1609.

324. Slotkin, T.A. and Seidler, F.J. (2009) Protein kinase C is a target for diverse developmental neurotoxicants: transcriptional responses to chlorpyrifos, diazinon, dieldrin and divalent nickel in PC12 cells. Brain Res. 1263, 23-32.

325. Slotkin, T.A., Seidler, F.J., and Fumagalli, F. (2008) Targeting of neurotrophic factors, their receptors, and signaling pathways in the developmental neurotoxicity of organophosphates in vivo and in vitro. Brain Res. Bull. 76, 424-438.

326. Hoogeboom, D., Essers, M.A., Polderman, P.E., Voets, E., Smits, L.M., and Burgering, B.M. (2008) Interaction of FOXO with $\{$ beta $\}$-catenin inhibits $\{$ beta $\}$-catenin/T cell factor activity. J. Biol. Chem. 283, 9224-9230.

327. Ferrara, N., Rinaldi, B., Corbi, G., Conti, V., Stiuso, P., Boccuti, S., Rengo, G., Rossi, F., and Filippelli, A. (2008) Exercise training promotes SIRT1 activity in aged rats. Rejuvenation Res. 11(1), 139-150.

328. Gilfillan, A.M. and Rivera, J. (2009) The tyrosine kinase network regulating mast cell activation. Immunol. Rev. 228, 149-169.

329. Li, F., Chong, Z.Z., and Maiese, K. (2005) Vital elements of the wnt-frizzled signaling pathway in the nervous system. Curr. Neurovasc. Res. 2, 331-340.

330. Dringen, R. (2005) Oxidative and antioxidative potential of brain microglial cells. Antioxid. Redox Signal. 7, 12231233.

331. Sankarapandi, S., Zweier, J.L., Mukherjee, G., Quinn, M.T., and Huso, D.L. (1998) Measurement and characterization of superoxide generation in microglial cells: evidence for an NADPH oxidase-dependent pathway. Arch. Biochem. Biophys. 353, 312-321.

332. Mehlhorn, G., Hollborn, M., and Schliebs, R. (2000) Induction of cytokines in glial cells surrounding cortical betaamyloid plaques in transgenic Tg2576 mice with Alzheimer pathology. Int. J. Dev. Neurosci. 18, 423-431.

333. Benzing, W.C., Wujek, J.R., Ward, E.K., Shaffer, D., Ashe, K.H., Younkin, S.G., and Brunden, K.R. (1999) Evidence for glial-mediated inflammation in aged APP(SW) transgenic mice. Neurobiol. Aging 20, 581-589.

334. Ferri, C., Giuggioli, D., Sebastiani, M., and Colaci, M. (2007) Treatment of severe scleroderma skin ulcers with recombinant human erythropoietin. Clin. Exp. Dermatol. 32, 287-290.

335. Thorne, M., Moore, C.S., and Robertson, G.S. (2009) Lack of TIMP-1 increases severity of experimental autoimmune encephalomyelitis: effects of darbepoetin alfa on TIMP-1 null and wild-type mice. J. Neuroimmunol. 211, 92-100.

336. Cuzzocrea, S., Mazzon, E., di Paola, R., Genovese, T., Patel, N.S., Britti, D., de Majo, M., Caputi, A.P., and Thiemermann, C. (2005) Erythropoietin reduces the degree of arthritis caused by type II collagen in the mouse. Arthritis Rheum. 52, 940-950.

337. Wu, Y., Shang, Y., Sun, S., Liang, H., and Liu, R. (2007) Erythropoietin prevents PC12 cells from 1-methyl-4phenylpyridinium ion-induced apoptosis via the Akt/GSK-3beta/caspase-3 mediated signaling pathway. Apoptosis 12, 1365-1375.

338. Li, F., Chong, Z.Z., and Maiese, K. (2004) Erythropoietin on a tightrope: balancing neuronal and vascular protection between intrinsic and extrinsic pathways. Neurosignals 13, 265-289.

339. Contaldo, C., Meier, C., Elsherbiny, A., Harder, Y., Trentz, O., Menger, M.D., and Wanner, G.A. (2007) Human recombinant erythropoietin protects the striated muscle microcirculation of the dorsal skinfold from postischemic injury in mice. Am. J. Physiol. Heart Circ. Physiol. 293, H274-283.

340. Vairano, M., Dello Russo, C., Pozzoli, G., Battaglia, A., Scambia, G., Tringali, G., Aloe-Spiriti, M.A., Preziosi, P., and Navarra, P. (2002) Erythropoietin exerts anti-apoptotic effects on rat microglial cells in vitro. Eur. J. Neurosci. 16, 584-592.

341. Cools, N., Ponsaerts, P., Van Tendeloo, V.F., and Berneman, Z.N. (2007) Regulatory T cells and human disease. Clin. Dev. Immunol. 2007, 89195.

342. Ebert, L.M., Tan, B.S., Browning, J., Svobodova, S., Russell, S.E., Kirkpatrick, N., Gedye, C., Moss, D., Ng, S.P., MacGregor, D., Davis, I.D., Cebon, J., and Chen, W. (2008) The regulatory T cell-associated transcription factor FoxP3 is expressed by tumor cells. Cancer Res. 68, 3001-3009.

343. Kono, K., Kawaida, H., Takahashi, A., Sugai, H., Mimura, K., Miyagawa, N., Omata, H., and Fujii, H. (2006) $\mathrm{CD} 4(+) \mathrm{CD} 25$ high regulatory $\mathrm{T}$ cells increase with tumor stage in patients with gastric and esophageal cancers. Cancer Immunol. Immunother. 55, 1064-1071.

344. Sela, U., Dayan, M., Hershkoviz, R., Cahalon, L., Lider, O., and Mozes, E. (2006) The negative regulators Foxj1 and Foxo3a are up-regulated by a peptide that inhibits systemic lupus erythematosus-associated T cell responses. Eur. J. Immunol. 36, 2971-2980. 
345. Bosque, A., Aguilo, J.I., Alava, M.A., Paz-Artal, E., Naval, J., Allende, L.M., and Anel, A. (2007) The induction of Bim expression in human T-cell blasts is dependent on nonapoptotic Fas/CD95 signaling. Blood 109, 1627-1635.

346. Lin, L., Hron, J.D., and Peng, S.L. (2004) Regulation of NF-kappaB, Th activation, and autoinflammation by the forkhead transcription factor Foxo3a. Immunity 21, 203-213.

347. Jonsson, H., Allen, P., and Peng, S.L. (2005) Inflammatory arthritis requires Foxo3a to prevent Fas ligand-induced neutrophil apoptosis. Nat. Med. 11, 666-671.

348. Ludikhuize, J., de Launay, D., Groot, D., Smeets, T.J., Vinkenoog, M., Sanders, M.E., Tas, S.W., Tak, P.P., and Reedquist, K.A. (2007) Inhibition of forkhead box class $O$ family member transcription factors in rheumatoid synovial tissue. Arthritis Rheum. 56, 2180-2191.

349. Kuo, C.C. and Lin, S.C. (2007) Altered FOXO1 transcript levels in peripheral blood mononuclear cells of systemic lupus erythematosus and rheumatoid arthritis patients. Mol. Med. 13, 561-566.

350. Fabre, S., Carrette, F., Chen, J., Lang, V., Semichon, M., Denoyelle, C., Lazar, V., Cagnard, N., DubartKupperschmitt, A., Mangeney, M., Fruman, D.A., and Bismuth, G. (2008) FOXO1 regulates L-selectin and a network of human T cell homing molecules downstream of phosphatidylinositol 3-kinase. J. Immunol. 181, 2980-2989.

351. Kikuchi, S., Nagai, T., Kunitama, M., Kirito, K., Ozawa, K., and Komatsu, N. (2007) Active FKHRL1 overcomes imatinib resistance in chronic myelogenous leukemia-derived cell lines via the production of tumor necrosis factorrelated apoptosis-inducing ligand. Cancer Sci. 98, 1949-1958.

352. Nowak, K., Killmer, K., Gessner, C., and Lutz, W. (2007) E2F-1 regulates expression of FOXO1 and FOXO3a. Biochim. Biophys. Acta 1769, 244-252.

353. Bouchard, C., Lee, S., Paulus-Hock, V., Loddenkemper, C., Eilers, M., and Schmitt, C.A. (2007) FoxO transcription factors suppress Myc-driven lymphomagenesis via direct activation of Arf. Genes Dev. 21, 2775-2787.

354. Lynch, R.L., Konicek, B.W., McNulty, A.M., Hanna, K.R., Lewis, J.E., Neubauer, B.L., and Graff, J.R. (2005) The progression of $\mathrm{LNCaP}$ human prostate cancer cells to androgen independence involves decreased FOXO3a expression and reduced p27KIP1 promoter transactivation. Mol. Cancer Res. 3, 163-169.

355. Li, Y., Wang, Z., Kong, D., Murthy, S., Dou, Q.P., Sheng, S., Reddy, G.P., and Sarkar, F.H. (2007) Regulation of FOXO3a/beta-catenin/GSK-3beta signaling by 3,3'-diindolylmethane contributes to inhibition of cell proliferation and induction of apoptosis in prostate cancer cells. J. Biol. Chem. 282, 21542-21550.

356. Cornforth, A.N., Davis, J.S., Khanifar, E., Nastiuk, K.L., and Krolewski, J.J. (2008) FOXO3a mediates the androgendependent regulation of FLIP and contributes to TRAIL-induced apoptosis of LNCaP cells. Oncogene 27, 44224433.

357. Yang, L., Xie, S., Jamaluddin, M.S., Altuwaijri, S., Ni, J., Kim, E., Chen, Y.T., Hu, Y.C., Wang, L., Chuang, K.H., $\mathrm{Wu}$, C.T., and Chang, C. (2005) Induction of androgen receptor expression by phosphatidylinositol 3-kinase/Akt downstream substrate, FOXO3a, and their roles in apoptosis of LNCaP prostate cancer cells. J. Biol. Chem. 280, 33558-33565.

358. Liu, P., Kao, T.P., and Huang, H. (2008) CDK1 promotes cell proliferation and survival via phosphorylation and inhibition of FOXO1 transcription factor. Oncogene 27, 4733-4744.

359. Kikuno, N., Shiina, H., Urakami, S., Kawamoto, K., Hirata, H., Tanaka, Y., Place, R.F., Pookot, D., Majid, S., Igawa, M., and Dahiya, R. (2007) Knockdown of astrocyte-elevated gene-1 inhibits prostate cancer progression through upregulation of FOXO3a activity. Oncogene 26, 7647-7655.

360. Trotman, L.C., Alimonti, A., Scaglioni, P.P., Koutcher, J.A., Cordon-Cardo, C., and Pandolfi, P.P. (2006) Identification of a tumour suppressor network opposing nuclear Akt function. Nature 441, 523-527.

361. Jin, G.S., Kondo, E., Miyake, T., Shibata, M., Takashima, T., Liu, Y.X., Hayashi, K., Akagi, T., and Yoshino, T. (2004) Expression and intracellular localization of FKHRL1 in mammary gland neoplasms. Acta Med. Okayama 58, 197-205.

362. Hu, M.C., Lee, D.F., Xia, W., Golfman, L.S., Ou-Yang, F., Yang, J.Y., Zou, Y., Bao, S., Hanada, N., Saso, H., Kobayashi, R., and Hung, M.C. (2004) IkappaB kinase promotes tumorigenesis through inhibition of forkhead FOXO3a. Cell 117, 225-237.

363. Sunters, A., Madureira, P.A., Pomeranz, K.M., Aubert, M., Brosens, J.J., Cook, S.J., Burgering, B.M., Coombes, R.C., and Lam, E.W. (2006) Paclitaxel-induced nuclear translocation of FOXO3a in breast cancer cells is mediated by c-Jun NH2-terminal kinase and Akt. Cancer Res. 66, 212-220.

364. Eddy, S.F., Kane, S.E., and Sonenshein, G.E. (2007) Trastuzumab-resistant HER2-driven breast cancer cells are sensitive to epigallocatechin-3 gallate. Cancer Res. 67, 9018-9023.

365. Zou, Y., Tsai, W.B., Cheng, C.J., Hsu, C., Chung, Y.M., Li, P.C., Lin, S.H., and Hu, M.C. (2008) Forkhead box transcription factor FOXO3a suppresses estrogen-dependent breast cancer cell proliferation and tumorigenesis. Breast Cancer Res. 10, R21.

366. Paik, J.H., Kollipara, R., Chu, G., Ji, H., Xiao, Y., Ding, Z., Miao, L., Tothova, Z., Horner, J.W., Carrasco, D.R., Jiang, S., Gilliland, D.G., Chin, L., Wong, W.H., Castrillon, D.H., and DePinho, R.A. (2007) FoxOs are lineagerestricted redundant tumor suppressors and regulate endothelial cell homeostasis. Cell 128, 309-323.

367. Delpuech, O., Griffiths, B., East, P., Essafi, A., Lam, E.W., Burgering, B., Downward, J., and Schulze, A. (2007) Induction of Mxi1-SR \{alpha\} by FOXO3a contributes to repression of Myc-dependent gene expression. Mol. Cell. Biol. 27, 4917-4930. 
368. Ticchioni, M., Essafi, M., Jeandel, P.Y., Davi, F., Cassuto, J.P., Deckert, M., and Bernard, A. (2007) Homeostatic chemokines increase survival of B-chronic lymphocytic leukemia cells through inactivation of transcription factor FOXO3a. Oncogene 26, 7081-7091.

369. Munoz-Fontela, C., Marcos-Villar, L., Gallego, P., Arroyo, J., Da Costa, M., Pomeranz, K.M., Lam, E.W., and Rivas, C. (2007) Latent protein LANA2 from Kaposi's sarcoma-associated herpesvirus interacts with 14-3-3 proteins and inhibits FOXO3a transcription factor. J. Virol. 81, 1511-1516.

370. Hoekstra, A.V., Ward, E.C., Hardt, J.L., Lurain, J.R., Singh, D.K., Buttin, B.M., Schink, J.C., and Kim, J.J. (2008) Chemosensitization of endometrial cancer cells through AKT inhibition involves FOXO1. Gynecol. Oncol. 108, 609618.

371. Donohue, J.M., Cevasco, M., and Rosenthal, M.B. (2007) A decade of direct-to-consumer advertising of prescription drugs. N. Engl. J. Med. 357, 673-681.

372. Mocini, D., Muso, P., Guendouz, E., De Marco, L., Mele, L., Cini, R., Sordini, P., Alois, A., Costantino, A., Arima, S., Gentili, C., and Santini, M. (2008) Endogenous erythropoietin and a single bolus of 40,000 IU of epoetin alpha do not protect the heart from ischaemia-reperfusion injury during extracorporeal circulation for cardiac surgery. Perfusion 23, 187-192.

373. Olea, F.D., Vera Janavel, G., De Lorenzi, A., Cuniberti, L., Yannarelli, G., Cabeza Meckert, P., Cearras, M., Laguens, R., and Crottogini, A. (2006) High-dose erythropoietin has no long-term protective effects in sheep with reperfused myocardial infarction. J. Cardiovasc. Pharmacol. 47, 736-741.

374. Goldberg, N., Lundin, A.P., Delano, B., Friedman, E.A., and Stein, R.A. (1992) Changes in left ventricular size, wall thickness, and function in anemic patients treated with recombinant human erythropoietin. Am. Heart J. 124, 424427.

375. Silverberg, D.S., Wexler, D., Sheps, D., Blum, M., Keren, G., Baruch, R., Schwartz, D., Yachnin, T., Steinbruch, S., Shapira, I., Laniado, S., and Iaina, A. (2001) The effect of correction of mild anemia in severe, resistant congestive heart failure using subcutaneous erythropoietin and intravenous iron: a randomized controlled study. J. Am. Coll. Cardiol. 37, 1775-1780.

376. Mancini, D.M., Katz, S.D., Lang, C.C., LaManca, J., Hudaihed, A., and Androne, A.S. (2003) Effect of erythropoietin on exercise capacity in patients with moderate to severe chronic heart failure. Circulation 107, 294-299.

377. Wu, H., Ren, B., Zhu, J., Dong, G., Xu, B., Wang, C., Zheng, X., and Jing, H. (2006) Pretreatment with recombined human erythropoietin attenuates ischemia-reperfusion-induced lung injury in rats. Eur. J. Cardiothorac. Surg. 29, 902-907.

378. Corwin, H.L., Gettinger, A., Fabian, T.C., May, A., Pearl, R.G., Heard, S., An, R., Bowers, P.J., Burton, P., Klausner, M.A., and Corwin, M.J. (2007) Efficacy and safety of epoetin alfa in critically ill patients. N. Engl. J. Med. 357, 965976.

379. Ioka, T., Tsuruoka, S., Ito, C., Iwaguro, H., Asahara, T., Fujimura, A., and Kusano, E. (2009) Hypertension induced by erythropoietin has a correlation with truncated erythropoietin receptor mRNA in endothelial progenitor cells of hemodialysis patients. Clin. Pharmacol. Ther. 86, 154-159.

380. van der Meer, P., Voors, A.A., Lipsic, E., Smilde, T.D., van Gilst, W.H., and van Veldhuisen, D.J. (2004) Prognostic value of plasma erythropoietin on mortality in patients with chronic heart failure. J. Am. Coll. Cardiol. 44, 63-67.

381. Reddy, M.K., Vasir, J.K., Hegde, G.V., Joshi, S.S., and Labhasetwar, V. (2007) Erythropoietin induces excessive neointima formation: a study in a rat carotid artery model of vascular injury. J. Cardiovasc. Pharmacol. Ther. 12, 237-247.

382. Henry, D.H., Bowers, P., Romano, M.T., and Provenzano, R. (2004) Epoetin alfa. Clinical evolution of a pleiotropic cytokine. Arch. Intern. Med. 164, 262-276.

383. Kanbay, M., Akcay, A., Delibasi, T., Uz, B., Kaya, A., Koca, C., Turgut, F., Bavbek, N., Uz, E., Duranay, M., and Yigitoglu, R. (2007) Comparison of effects of darbepoetin alfa and epoetin alfa on serum endothelin level and blood pressure. Adv. Ther. 24, 346-352.

384. Kokhaei, P., Abdalla, A.O., Hansson, L., Mikaelsson, E., Kubbies, M., Haselbeck, A., Jernberg-Wiklund, H., Mellstedt, H., and Osterborg, A. (2007) Expression of erythropoietin receptor and in vitro functional effects of epoetins in B-cell malignancies. Clin. Cancer Res. 13, 3536-3544.

385. Hardee, M.E., Rabbani, Z.N., Arcasoy, M.O., Kirkpatrick, J.P., Vujaskovic, Z., Dewhirst, M.W., and Blackwell, K.L. (2006) Erythropoietin inhibits apoptosis in breast cancer cells via an Akt-dependent pathway without modulating in vivo chemosensitivity. Mol. Cancer Ther. 5, 356-361.

386. Lai, S.Y. and Grandis, J.R. (2006) Understanding the presence and function of erythropoietin receptors on cancer cells. J. Clin. Oncol. 24, 4675-4676.

387. Ceelen, W., Boterberg, T., Smeets, P., Van Damme, N., Demetter, P., Zwaenepoel, O., Cesteleyn, L., Houtmeyers, P., Peeters, M., and Pattyn, P. (2007) Recombinant human erythropoietin alpha modulates the effects of radiotherapy on colorectal cancer microvessels. Br. J. Cancer 96, 692-700.

388. Rades, D., Golke, H., Schild, S.E., and Kilic, E. (2008) The impact of tumor expression of erythropoietin receptors and erythropoietin on clinical outcome of esophageal cancer patients treated with chemoradiation. Int. J. Radiat. Oncol. Biol. Phys. 71, 152-159.

389. Ning, S., Hartley, C., Molineux, G., and Knox, S.J. (2005) Darbepoietin alfa potentiates the efficacy of radiation therapy in mice with corrected or uncorrected anemia. Cancer Res. 65, 284-290. 
390. Sigounas, G., Sallah, S., and Sigounas, V.Y. (2004) Erythropoietin modulates the anticancer activity of chemotherapeutic drugs in a murine lung cancer model. Cancer Lett. 214, 171-179.

391. Joyeux-Faure, M. (2007) Cellular protection by erythropoietin: new therapeutic implications? J. Pharmacol. Exp. Ther. 323, 759-762.

392. Baoutina, A., Alexander, I.E., Rasko, J.E., and Emslie, K.R. (2007) Potential use of gene transfer in athletic performance enhancement. Mol. Ther. 15, 1751-1766.

393. Diamanti-Kandarakis, E., Konstantinopoulos, P.A., Papailiou, J., Kandarakis, S.A., Andreopoulos, A., and Sykiotis, G.P. (2005) Erythropoietin abuse and erythropoietin gene doping: detection strategies in the genomic era. Sports Med. 35, 831-840.

394. Segura, J., Pascual, J.A., and Gutierrez-Gallego, R. (2007) Procedures for monitoring recombinant erythropoietin and analogues in doping control. Anal. Bioanal. Chem. 388, 1521-1529.

395. Frietsch, T., Maurer, M.H., Vogel, J., Gassmann, M., Kuschinsky, W., and Waschke, K.F. (2007) Reduced cerebral blood flow but elevated cerebral glucose metabolic rate in erythropoietin overexpressing transgenic mice with excessive erythrocytosis. J. Cereb. Blood Flow Metab. 27, 469-476.

396. Eliopoulos, N., Gagnon, R.F., Francois, M., and Galipeau, J. (2006) Erythropoietin delivery by genetically engineered bone marrow stromal cells for correction of anemia in mice with chronic renal failure. J. Am. Soc. Nephrol. 17, 15761584.

397. Orive, G., De Castro, M., Ponce, S., Hernandez, R.M., Gascon, A.R., Bosch, M., Alberch, J., and Pedraz, J.L. (2005) Long-term expression of erythropoietin from myoblasts immobilized in biocompatible and neovascularized microcapsules. Mol. Ther. 12, 283-289.

398. Ponce, S., Orive, G., Hernandez, R.M., Gascon, A.R., Canals, J.M., Munoz, M.T., and Pedraz, J.L. (2006) In vivo evaluation of EPO-secreting cells immobilized in different alginate-PLL microcapsules. J. Control Release 116, 2834.

399. Doolittle, N.D., Peereboom, D.M., Christoforidis, G.A., Hall, W.A., Palmieri, D., Brock, P.R., Campbell, K.C., Dickey, D.T., Muldoon, L.L., O'Neill, B.P., Peterson, D.R., Pollock, B., Soussain, C., Smith, Q., Tyson, R.M., and Neuwelt, E.A. (2007) Delivery of chemotherapy and antibodies across the blood-brain barrier and the role of chemoprotection, in primary and metastatic brain tumors: report of the Eleventh Annual Blood-Brain Barrier Consortium meeting. J. Neurooncol. 81, 81-91.

400. Gonzalez, F.F., McQuillen, P., Mu, D., Chang, Y., Wendland, M., Vexler, Z., and Ferriero, D.M. (2007) Erythropoietin enhances long-term neuroprotection and neurogenesis in neonatal stroke. Dev. Neurosci. 29, 321-330.

401. Slevin, M., Kumar, P., Gaffney, J., Kumar, S., and Krupinski, J. (2006) Can angiogenesis be exploited to improve stroke outcome? Mechanisms and therapeutic potential. Clin. Sci. (Lond.) 111, 171-183.

402. Ward, E.C., Hoekstra, A.V., Blok, L.J., Hanifi-Moghaddam, P., Lurain, J.R., Singh, D.K., Buttin, B.M., Schink, J.C., and Kim, J.J. (2008) The regulation and function of the forkhead transcription factor, Forkhead box O1, is dependent on the progesterone receptor in endometrial carcinoma. Endocrinology 149, 1942-1950.

403. Hellwinkel, O.J., Rogmann, J.P., Asong, L.E., Luebke, A.M., Eichelberg, C., Ahyai, S., Isbarn, H., Graefen, M., Huland, H., and Schlomm, T. (2008) A comprehensive analysis of transcript signatures of the phosphatidylinositol-3 kinase/protein kinase B signal-transduction pathway in prostate cancer. BJU Int. 101, 1454-1460.

404. Kim, J.H., Kim, M.K., Lee, H.E., Cho, S.J., Cho, Y.J., Lee, B.L., Lee, H.S., Nam, S.Y., Lee, J.S., and Kim, W.H. (2007) Constitutive phosphorylation of the FOXO1A transcription factor as a prognostic variable in gastric cancer. Mod. Pathol. 20, 835-842.

405. Zethelius, B., Berglund, L., Sundstrom, J., Ingelsson, E., Basu, S., Larsson, A., Venge, P., and Arnlov, J. (2008) Use of multiple biomarkers to improve the prediction of death from cardiovascular causes. N. Engl. J. Med. 358, 21072116.

406. Brunet, A., Sweeney, L.B., Sturgill, J.F., Chua, K.F., Greer, P.L., Lin, Y., Tran, H., Ross, S.E., Mostoslavsky, R., Cohen, H.Y., Hu, L.S., Cheng, H.L., Jedrychowski, M.P., Gygi, S.P., Sinclair, D.A., Alt, F.W., and Greenberg, M.E. (2004) Stress-dependent regulation of FOXO transcription factors by the SIRT1 deacetylase. Science 303, 20112015.

407. Bakker, W.J., Harris, I.S., and Mak, T.W. (2007) FOXO3a is activated in response to hypoxic stress and inhibits HIF1-induced apoptosis via regulation of CITED2. Mol. Cell 28, 941-953.

408. Han, C.Y., Cho, K.B., Choi, H.S., Han, H.K., and Kang, K.W. (2008) Role of FoxO1 activation in MDR1 expression in adriamycin-resistant breast cancer cells. Carcinogenesis 29, 1837-1844.

409. Emami, K.H. and Corey, E. (2007) When prostate cancer meets bone: control by wnts. Cancer Lett. 253, 170-179.

\section{This article should be cited as follows:}

Maiese, K., Hou, J., Chong, Z.Z., and Shang, Y.C. (2009) Erythropoietin, forkhead proteins, and oxidative injury: biomarkers and biology. TheScientificWorldJOURNAL 9, 1072-1104. DOI 10.1100/tsw.2009.121. 

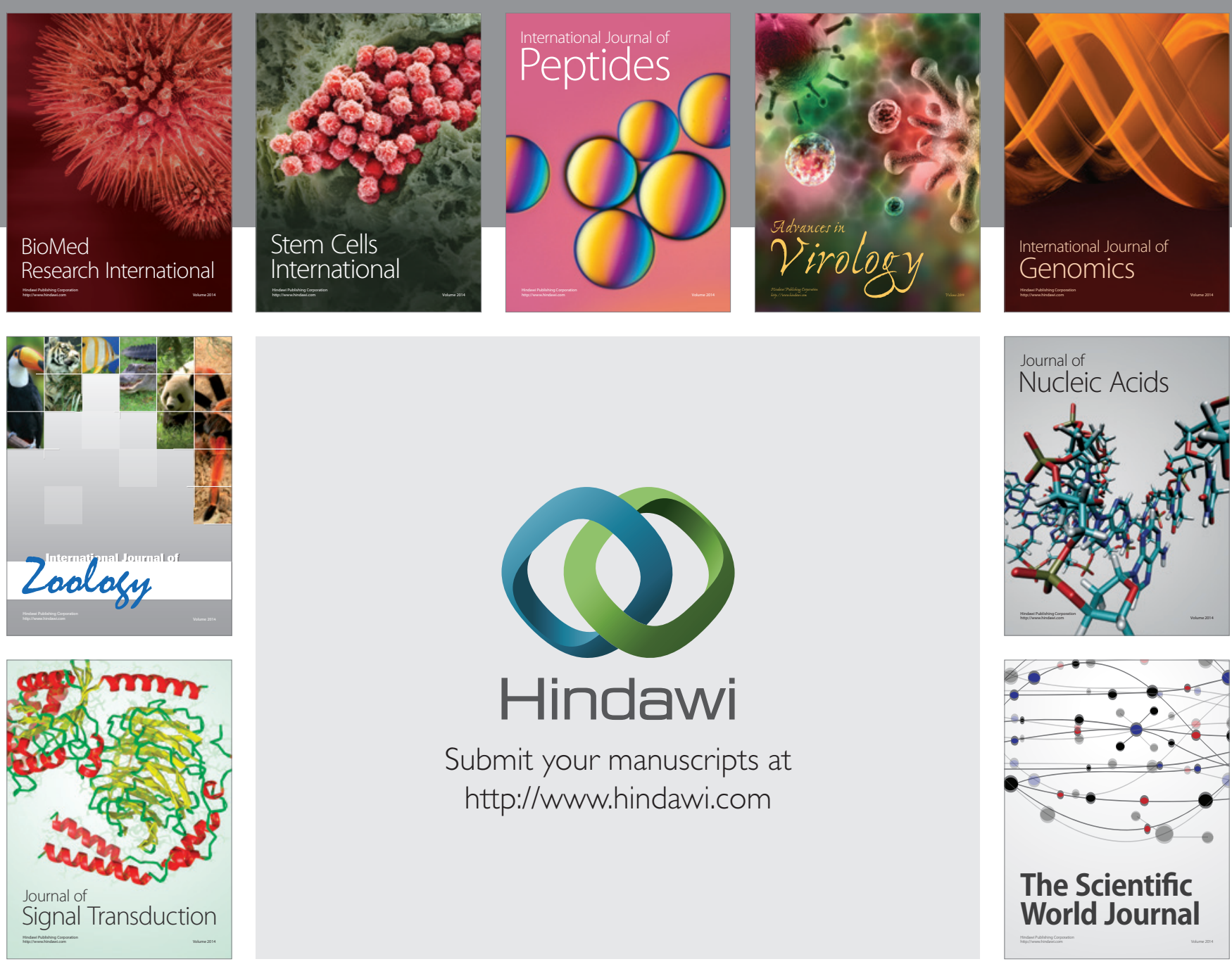

Submit your manuscripts at

http://www.hindawi.com
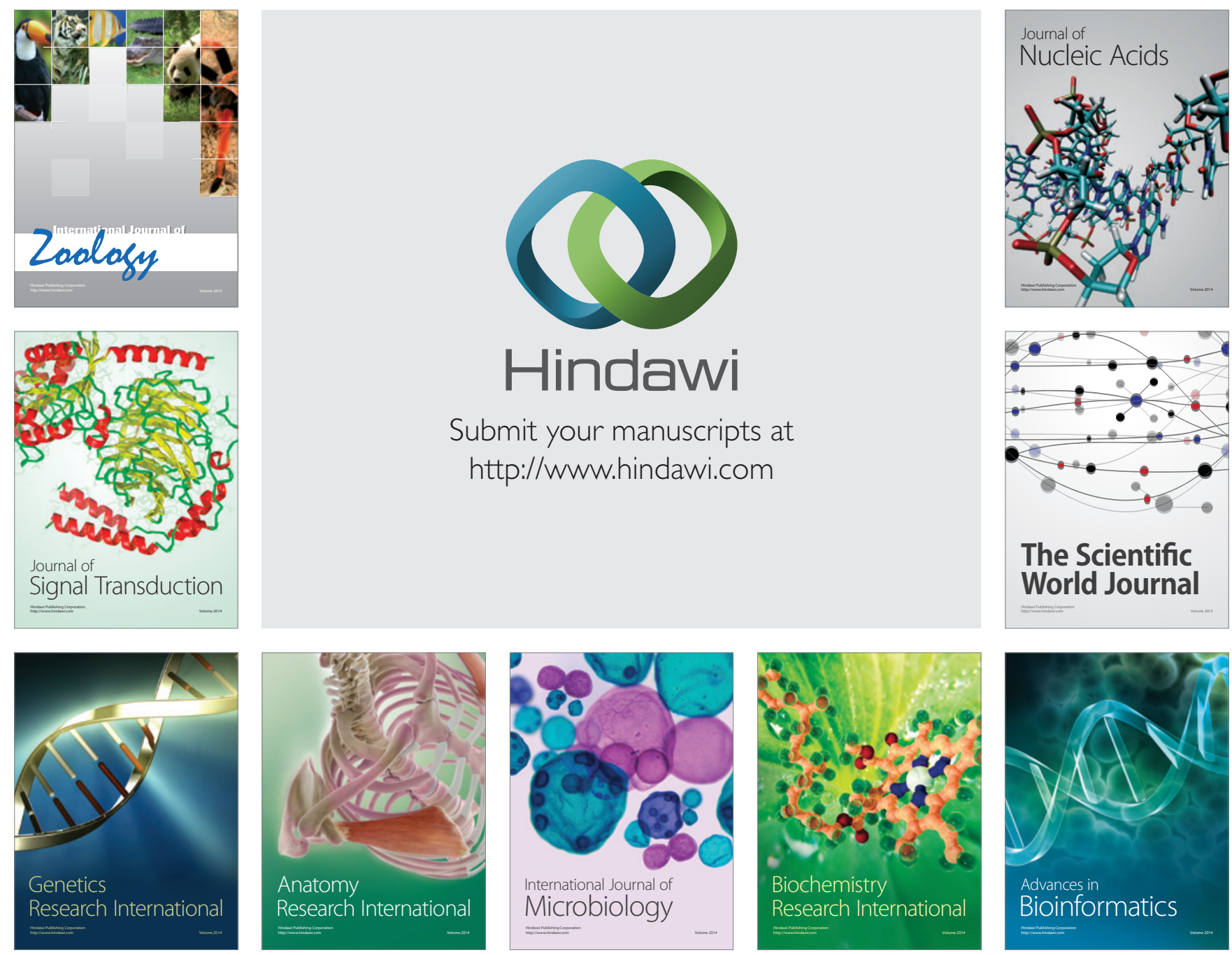

The Scientific World Journal
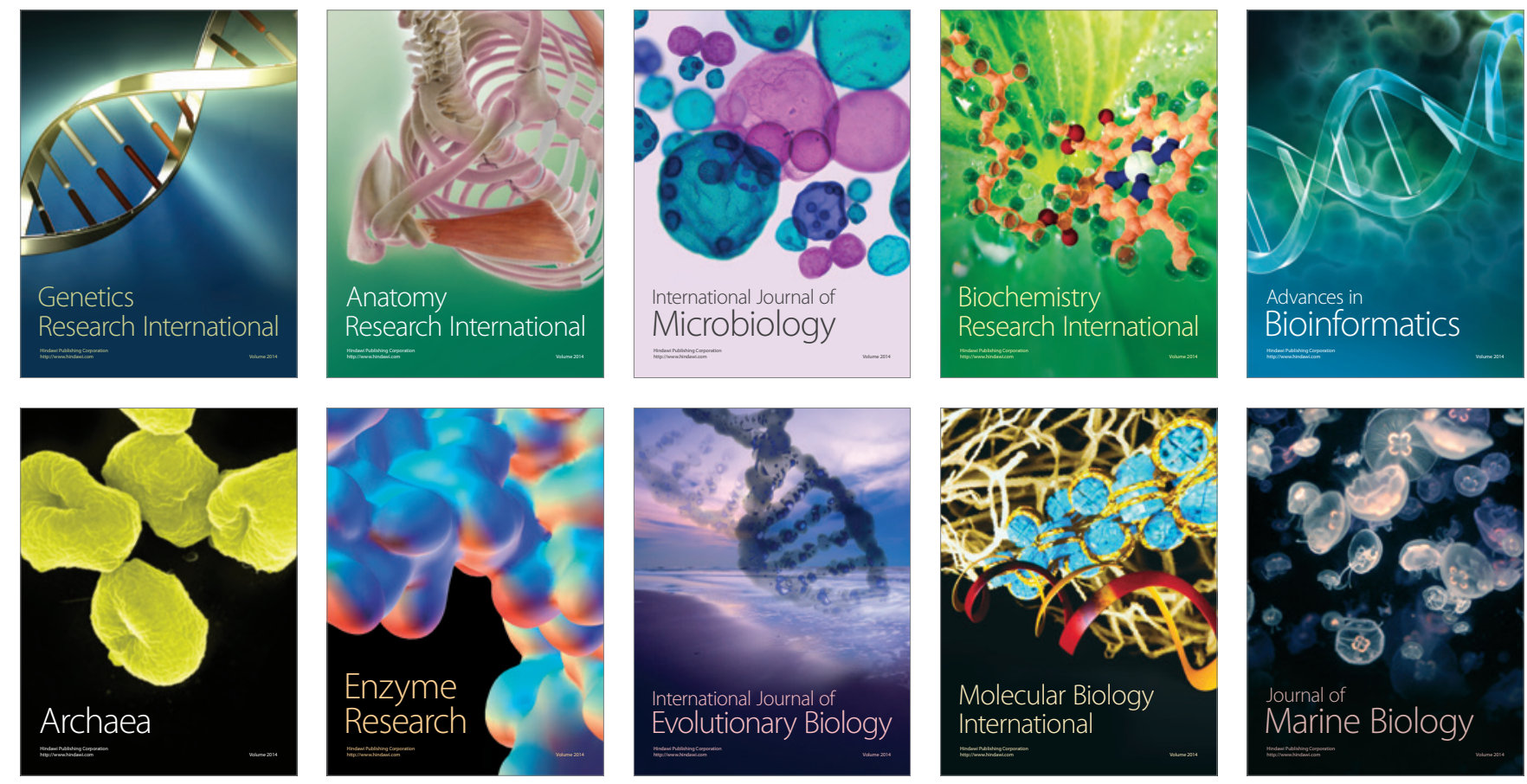